\title{
Financial Benchmarks: Proposing A Governance Framework based on Free-riders, Stakeholders and the Public Interest
}

\section{Iris H-Y Chiu*}

\section{Abstract}

This article discusses the regulation of financial benchmarks and suggests an appropriate regulatory design that harnesses the benefits of market-based governance and yet meets the objectives of regulatory governance. The article argues that the existing regulatory regime in the UK, the proposed regulatory framework in the EU and the IOSCO-OICU recommendations are based on achieving some balance between market-based and regulatory governance for benchmarks, but certain aspects of these regimes could compromise regulatory goals while not optimally harnessing market-based governance. The article advocates the adoption of a user-centric analysis to first determine the nature of financial benchmarks and argues that the scope and design of regulation for financial benchmarks should be based on that fundamental analysis. The regulatory framework should then address the healthy balance between market-based and regulatory governance for the benchmarks determined to be appropriately subject to regulation.

\section{Introduction}

Financial benchmarks used to fall within an area of self-regulation up until the uncovering of the manipulation scandals related to interest-rate benchmarks such as the London Interbank Offered Rate and price benchmarks such as the London foreign exchange ' 4 pm fix'. Self-regulation has not been inappropriate for financial benchmarks as they are by nature privately-produced goods for market transactions. However, a number of widely used financial benchmarks were subject to the influence of a few market players, while being adopted by millions of stakeholders worldwide. Benchmark manipulation could and did take place, such as in relation to the London Interbank Offered Rate (LIBOR). Although it is difficult to prove causation of loss to individual contracting parties due to such manipulation, the integrity of the benchmark and market confidence were damaged. The revelations that banks such as Barclays, ${ }^{1} \mathrm{UBS}^{2}$ and JP Morgan ${ }^{3}$ have been engaged in manipulative relating to LIBOR, the WMR London fix for foreign exchange trading and the London

\footnotetext{
*Reader in Laws, University College London.

1 'Timeline: Barclays Libor-fixing Scandal', BBCNews (6 Feb 2013) at http://www.bbc.co.uk/news/business18671255; 'Barclays fined $£ 26 \mathrm{~m}$ for failings surrounding the London Gold Fixing', FCA Press Release (23 May 2014) at https://fca.org.uk/news/barclays-fined-26m-for-failings-surrounding-the-london-gold-fixing.

2 'UBS traders charged, bank fined \$1.5 billion in Libor scandal', Reuters (19 Dec 2012); 'UBS to settle allegations over precious metals trading', Financial Times (9 Nov 2014).

3 'Foreign exchange: The big fix', Financial Times (12 Nov 2013) discussing 15 banks including JP Morgan in potential enforcement action against foreign exchange fixing.
} 
gold fix have raised concerns globally as to the need to protect the market from toxic financial sector culture $^{4}$ that has existed way before the global financial crisis of 2008-9.

The UK Financial Conduct Authority has stepped in to regulate the LIBOR benchmark ${ }^{5}$ and will include in its regulatory regime seven other benchmarks from 1 April $2015 .{ }^{6} \mathrm{~A}$ review ${ }^{7}$ is also underway to consider an appropriate governance framework for maintaining fair and effective markets in the UK, including the role of financial benchmarks. The Fair and Effective Markets Review was established by the UK Chancellor in June 2014, to conduct a comprehensive and forward-looking assessment of the way wholesale financial markets operate. The aim is to produce a comprehensive survey and recommendations that would holistically address issues of trust and confidence in wholesale markets, to help restore trust in those markets and influence the international debate on trading practices. ${ }^{8}$ The Review states that their concern is with financial benchmarks that are UKbased, of significant importance to the financial markets and relating to which serious misconduct concerns have arisen. ${ }^{9}$

Legislation in the European Union is being developed for financial benchmarks in general, ${ }^{10}$ and international standards under the OICU-IOSCO ${ }^{11}$ have been introduced. The governance schemes

\footnotetext{
4 Justin O'Brien, 'Singapore Sling: How Coercion May Cure the Hangover in Financial Benchmark Governance' (2013) at http://ssrn.com/abstract=2350445.

*PhD, LLM, Reader in Laws, University College London.

${ }^{5}$ The Wheatley Review of LIBOR (Final Report Sep 2012); Financial Conduct Autority (FCA) Handbook, MAR 8.

${ }^{6}$ http://fca.org.uk/news/fca-to-regulate-seven-additional-financial-benchmarks.

${ }^{7}$ Fair and Effective Markets Review, How Fair and Effective are the Fixed Income, Foreign Exchange and Commodities Markets? (Oct 2014).
}

${ }^{8}$ http://www.bankofengland.co.uk/markets/Pages/fmreview.aspx. The benchmarks identified therein will be subject to FCA regulation from 1 April 2015. See http://fca.org.uk/news/fca-to-regulate-seven-additionalfinancial-benchmarks.

\footnotetext{
${ }^{9}$ The scope of financial benchmarks highlighted for regulatory attention is based on the scale of use and hence impact upon the market if the benchmark were impeached- 'In judging whether a benchmark could be regarded as 'major', the Review had regard to a number of indicators, including the number and value of financial contracts directly or indirectly linked to the benchmark, the range of different usages to which the benchmark is put, and the degree of market recognition. In the Review's judgment, it is these benchmarks that would have the biggest impact on retail and wholesale investors if they were distorted or abused, and would represent the greatest source of systemic vulnerability and risk if their integrity were questioned.' See Fair and Effective Markets Review, Recommendations on Additional Financial Benchmarks to Be Brought into UK Regulatory Scope (Report to HM Treasury, Aug 2014) at para 28.

${ }^{10}$ European Commission, Proposal for a Regulation of the European Parliament and of the Council on indices used as benchmarks in financial instruments and financial Contracts (27 Oct 2014, version Presidency compromise text).

${ }^{11}$ OICU and IOSCO, Principles for Financial Benchmarks: Final Report (July 2013).
} 
proposed/implemented (where LIBOR is concerned) ${ }^{12}$ at the UK, EU and international levels are broadly similar, and converge along the themes of maintaining the existing profile of benchmarks while introducing governance frameworks in order to restore market confidence in the existing benchmarks. The current frameworks attempt to balance regulatory governance ${ }^{13}$ with aspects of market-based governance. These frameworks do not treat the regulated financial benchmark as a public good per se and this article argues that this is the right approach. However, this article will argue that certain aspects of the current regulatory frameworks fail to adopt an optimal balance between regulatory and market-based governance and hence over-regulate certain areas and underregulate other crucial respects.

This article first considers why and which aspects of financial benchmarks ought to be subject to regulatory governance. Section A adopts a user-centric analysis and aspects of behavioural economics to analyse the nature of financial benchmarks in order to derive an appropriate scope for regulatory governance. Section B discusses the limitations of market-based governance to meet secondary users' needs and discusses the optimal extent of regulatory governance and the design of such governance frameworks. Mapping this analysis onto a critical study of the current regulatory frameworks, Section $\mathrm{C}$ suggests that there are the current regulatory frameworks could be adjusted to more appropriately navigate the interface between market-based and public interest concerns, and explores an alternative approach. Section D concludes.

\section{A. A User-Centric Analysis for Financial Benchmarks and Defining the Scope of 'Regulable Benchmarks'}

A financial benchmark can be in the form of an interest rate benchmark which serves the purpose of sign-posting the cost of credit at any one time. An interest rate benchmark like the London Interbank Offered Rate (LIBOR) provides a basis for the calculation of the price of debt over a period of time. As debt contracts need to mature, whether in the short term or longer term, parties to such a contract who have to agree on the price of debt at the outset are unable to fix the price where the value of a currency inherently fluctuates according to changes in interest rate. Benchmarking the price of a debt contract allows for limited flexibility and the best-possible certainty in determining price in an incomplete contracting situation. The benchmark device thus saves on future transaction costs in terms of research and negotiation costs over the period of the contract. It acts as a facilitator for trust and access to such transactions, and serves the wider economic objective of democratising access to credit. ${ }^{14}$ The LIBOR was first developed in the $1980 \mathrm{~s}^{15}$ to facilitate the syndicated loans market, which allowed groups of banks together to fund large corporate borrowings and to share risks. In order to arrive at a price of debt that would be agreeable to all in the most cost-effective manner, the use of an interest rate benchmark to price the loan over the

\footnotetext{
${ }^{12}$ FCA Handbook, MAR 8.

${ }^{13}$ Fair and Effective Markets Review, Recommendations on Additional Financial Benchmarks to Be Brought into UK Regulatory Scope (Report to HM Treasury, Aug 2014).

${ }^{14}$ Darrell Duffir, Piotr Dworczak and Haoxiang Zhu, 'Benchmarks in Search Markets' (2014) at http://ssrn.com/abstract=2515582.

${ }^{15}$ The Wheatley Review of LIBOR (Final Report Sep 2012) at p.75.
} 
term seemed most efficacious and sensible. LIBOR has been generated by banks in the syndicated loans market, but the adoption of LIBOR to price debt contracts has extended way beyond the primary users that are financial institutions.

Other financial benchmarks that serve the purpose of price discovery and the reduction of transaction costs are found in contracts that involve currency exchanges, e.g. the WM Reuters 4pm fix for foreign exchange; and commodities whose prices are subject to regular fluctuations in market discovery, e.g. the London gold fix and LBMA silver fix, and the ICE Brent futures for crude oil. ${ }^{16}$ These are largely used in the wholesale sector.

Another type of financial benchmark would be indices that aggregate the financial performance of financial assets in a trading market, such as stock market indices. A stock market index such as the FTSE100 is a share index of the 100 companies listed on the London Stock Exchange with the highest market capitalisation. Hence, the FTSE100 can be used as a benchmark to evaluate the performance of large cap securities. Stock market indices ${ }^{17}$ are generally useful as benchmarks for evaluating investment performance. Asset owners such as pension and collective investment funds would often contractually stipulate that asset managers' performance be evaluated according to a choice of stock market indices. ${ }^{18}$ Individual private wealth management can also be structured along those lines.

Another type of financial benchmark would be indices that indicate certain macro-economic findings that take stock of the current state of an economy or indicate certain trends ahead. These may be used in incomplete contracts for longer term price determination, or used in informing public policy decision-making and strategic decision-making in the private sector. For example, the consumer price index (CPI) measures changes in the price level of a market basket of consumer goods and services purchased by households. Changes in the CPI may indicate changes in inflation, and can affect wages and pensions obligations. The Gross Domestic Product (GDP) is also an index that falls within this typology, measuring the level of output in a domestic economy in order to determine economic performance. GDP information feeds into public policy making and strategic private sector decisions such as investment and development.

\footnotetext{
${ }^{16}$ All identified as important benchmarks in Fair and Effective Markets Review, Recommendations on Additional Financial Benchmarks to Be Brought into UK Regulatory Scope (Report to HM Treasury, Aug 2014).

${ }^{17}$ Another example is the Standard and Poor 500 is an index constructed out of the largest 500 American companies listed on the New York Stock Exchange and Nasdaq. It includes other weightings besides size of capitalisation, such as liquidity, domicile, public float, sector classification, financial viability, length of time publicly traded and listing exchange. See S\&P U.S. Indices Methodology at http://www.standardandpoors.com/servlet/BlobServer?blobheadername3=MDT-

Type\&blobcol=urldata\&blobtable=MungoBlobs\&blobheadervalue $2=$ inline $\% 3 \mathrm{~B}+$ filename\%3Dmethodology-spus-indices.pdf\&blobheadername $2=$ Content -

Disposition\&blobheadervalue1=application\%2Fpdf\&blobkey=id\&blobheadername1=contenttype\&blobwhere $=1244125623286 \&$ blobheadervalue $3=$ UTF-8.

${ }^{18}$ Lodewjik van Setten, The Law of Institutional Investment Management (Oxford: Oxford University Press 2009) at para $4.48 \mathrm{ff} ; 4.86 \mathrm{ff}$.
} 
Rauterberg and Verstein ${ }^{19}$ describe the different types of financial benchmarks as falling within three typologies- the product index, the by-product index and the public index. The typologies are constructed from the producers' perspectives. The product index is constructed by the relevant exchange or institution that sells the index through licensing use, as it is a market good developed to meet information and evaluation needs. The stock market and securities indices fall within this category. The by-product index is a benchmark that is developed in order to facilitate other transactions, and so it is not an end-product in itself. The interest rate and market instrument indices fall within this typology. The public indices are developed as information goods that serve a wide range of purposes and can be treated akin to public goods. The authors take the view that the producers' perspective is the important one for classifying these indices. The producers' perspective highlights the nature of incentives that accompany production and an examination of those incentives can reveal the weaknesses in the reliability of these benchmarks, if any. Product indices are produced for sale with a view to profit, and hence the producer has every incentive to make the index robust to maintain market trust and adoption. Public indices are produced for public interest purposes generally by government or not-for-profit groups and hence the integrity of the indices is maintained by producers' commitments. By-product indices are however only facilitative in nature and producers are less committed to their quality as long as transactions are not affected. Further the lack of producer commitment to maintain the quality of the indices could be ascribed to a tragedy of the commons situation. The authors hence recommend that the weaknesses in LIBOR flow from its nature as a by-product index, and the quality of such an index can only be improved if by-producers are allowed to become producers, having stronger intellectual property and proprietary rights over these indices so that they can profit out of index production. In this way, the quality of by-product indices can be improved..$^{20}$

The main critique against Rauterberg and Verstein's suggestion is that access to the use of byproduct indices would become restricted ${ }^{21}$ which is an undesirable consequence. Undiscriminating access is itself very valuable to the wider objectives of democratising access to financial transactions, and the 'proprietisation' of a by-product index which is intended to facilitate transactions in the market seems counter-intuitive to its facilitative properties. This article suggests that the producercentric perspective adopted by Rauterberg and Verstein may be incomplete, and proposes to take the opposite perspective from the producers' point of view with regard to the nature of a financial benchmark. It argues that the appropriate governance mechanism for financial benchmarks should be designed according to the types of users the benchmark attracts. The user perspective helps in shaping the scope of governance, and behavioural observations in relation to users can be used to inform of appropriate designs in governance frameworks.

\footnotetext{
${ }^{19}$ Gabriel Rauterberg and Andrew Verstein, 'Index Theory: The Law, Promise and Failure of Financial Indices' (2013) 30 Yale Journal of Law and Regulation 101.

${ }^{20}$ The ICE'S administration of LIBOR now adopts this model to a certain extent, see ICE, Position Paper on the Evolution of ICE LIBOR (20 Oct 2014). ICE, Position Paper on the Evolution of ICE LIBOR (20 Oct 2014).

${ }^{21}$ Stephen Bainbridge, 'Reforming LIBOR: Wheatley versus the Alternatives' (2013) 9 NYU Journal of Law and Business 789.
} 
The article suggests that financial benchmarks may be classified into 'primary use' benchmarks and 'primary plus secondary use' benchmarks. 'Primary use' benchmarks can only be used upon payment for a licence and cannot be freely redistributed. The stock market and securities indices such as the FTSE and Standard and Poor indices fall into this category. Each index has different proprietary characteristics that suit different investment portfolio assessment needs. Hence, they are not capable of easy redistribution. Producers and users are in a symbiotic relationship as users' needs in investment performance evaluation feed into index design and production. The high level of bilateralism enjoyed between producers and users in the market for such 'primary use' benchmarks ensures high levels of commitment to production quality for users. Further, primary users' adoption of certain indices is used as a distinguishing characteristic in the competition for mandates among asset managers. As 'primary-use' benchmarks are characterised by a high level of bilateralism between benchmark producers and users, such a market is capable of being self-governing to meet its' constituents' needs.

However, 'primary plus secondary use' benchmarks are those benchmarks that may/may not be produced with wide dissemination in mind, but are nevertheless capable of free redistribution and wide dissemination. This may be because the benchmark is readily observable and easy to redistribute, and producers have no incentive to restrict use. Where LIBOR is concerned, although the development of the benchmark was for the purpose of providing the necessary mechanism for banks in a syndicated loan group to enter into such transactions in a cost-effective manner, the primary users have no incentive to restrict use and indeed every incentive to promote use as the benchmark device could then be used to overcome transaction costs in other syndicated loan transactions, credit and structured credit transactions, derivative transactions and so on. The benchmark device was crucial for the development of transaction and risk management technologies generally. In as much as benchmark development promoted access to financial transactions, and hence a form of democratisation of finance, it also promoted growth and expansion in financial intermediation and served financial institutions' private benefits. Even if a completely secondary market outside of the mainstream financial sector developed in the use of such benchmarks, such as in corporate lending or between peer lenders and borrowers, that is still beneficial to the mainstream financial sector as connections and linkages with financial institutions can be made in the web of transactions and risk management. In sum, 'primary plus secondary use' benchmarks are inherently susceptible to free-riding as they are by nature not difficult to distribute, and producers do not have incentives either to limit distribution.

Where 'public indices' are concerned, the producers have information dissemination and public education in mind and it would be contrary to the nature of such indices to limit distribution for profit. Public indices arguably attain the status of public goods. Where a benchmark may be capable of 'primary plus secondary use', there arises the asymmetry of power between producers and users, giving rise to opportunities for abuse, such as in the LIBOR manipulation scandal. This problem is particularly acute with the by-product indices.

Where a 'primary plus secondary use' benchmark becomes widely disseminated and used, secondary users are free-riders in the market. But this Section argues that they should be regarded as stakeholders, because secondary users, although being free-riders, are not 'squatters'. Their adoption and use of a financial benchmark adds value to the benchmark by collective affirmation, strengthening a benchmark's appeal and leadership. This is beneficial to the primary users as a 
positive feedback loop effect that reinforces the credibility of that benchmark. Hence, primary users have no incentive to limit secondary use and do not take steps to inhibit such use, on the contrary, the promotion of secondary use is encouraged. Hence, free-riding secondary users should be treated as stakeholders in the relevant benchmark. This article argues that the 'stakeholder' framing of secondary users of such a benchmark allows us to derive an appropriate scope for considering what benchmarks ought to be governed so as to take into account of stakeholders' interests that are not represented in the production process.

The needs of secondary users as stakeholders revolve around the maintenance of the quality of the benchmark as a perceived 'best-price determination mechanism' and the comparability effects brought about by contractual standardisation around the well-accepted benchmark. Even if freeriders do not participate in benchmark production and do not have an initial right in demanding that the benchmark they have come to adopt meets certain quality expectations, their persistent reliance may give rise to certain legitimate expectations due to their trust and reliance, and a grave disappointment in the quality of the benchmark would result in uncertainty for transactions and market instability. The recognition of stakeholder interests means that we should consider how the accountability gap to stakeholders should be addressed. Further, the vulnerability of stakeholders in their reliance upon benchmark quality could become a wider issue of market confidence. Where a well-accepted 'primary plus secondary use' benchmark like LIBOR is concerned, the conditions of production have remained unchanged for primary use ${ }^{22}$ and have become disengaged from the implications of widespread secondary use of the benchmark. Under these conditions, the setting of the benchmark does not take into account of stakeholder interests or accountability to stakeholders, and hence does not promise that its quality can be relied upon. Further, the setting of the benchmark can be susceptible to opaque manipulation contrary to secondary users' interests, which is revealed to have taken place with respect to many major banks involved in the LIBOR setting process. $^{23}$

Hence, the appropriate scope of regulatory governance for benchmarks should comprise of 'primary plus secondary use' benchmarks where a governance deficit occurs due to the estrangement between production and secondary use and where secondary user trust and confidence could become a wider issue affecting market stability. The extension of regulatory governance over such benchmarks can be justified on two fronts. First, the secondary user base consists of stakeholders who are affected by and not able to exert governance over the integrity of the benchmark, and hence this is a governance deficit. One may argue that the governance deficit is the private trade-off for free-riding and hence regulatory governance should not intervene to make the stakeholders' positions better. However, one could also counter-argue that if we accept secondary users as legitimate stakeholders, then the governance deficit is a market failure and hence warrants regulatory intervention. Nevertheless and secondly, where the stakeholder base is large, the nature of the governance deficit may become a concern in public interest due to the scale of social reliance

\footnotetext{
${ }^{22}$ V Brousseau, A Chailloux and A Durré, 'Fixing the Fixings: What Road to a More Representative Money Market Benchmark?' (IMF Working Paper 2013).

${ }^{23}$ These problems were discussed in Dan Awrey, 'The Limits of Private Market Ordering within Modern Financial Markets' (2015) 34 Review of Banking and Financial Law, forthcoming at http://papers.ssrn.com/sol3/papers.cfm?abstract id=2262712.
} 
and the needs of overall market confidence. The rationale for introducing a regulatory framework for governing benchmarks is thus based on the public interest of protecting market stability, even if such public interest arises as a consequence of the widespread adoption of a private market good. This public interest rationale endorses the position of secondary users as stakeholders of benchmark production processes, even if they are free-riders to begin with. In instituting governance reforms for 'primary plus secondary use' benchmarks such as LIBOR, and other 'price-determination' benchmarks highlighted in the Fair and Effective Markets Review, ${ }^{24}$ public authorities seem to have taken the same position- that benchmark production needs to conform to certain stakeholder expectations in order to maintain trust in and use of the benchmark. In addition to LIBOR, the Fair and Effective Markets Review ${ }^{25}$ recommends that six other widely-used benchmarks that function as price-determination mechanisms be subject to governance and oversight and these recommendations have been taken up by the FCA which will include those benchmarks in its regulatory regime from April 2015. ${ }^{26}$

The next Section elaborates on why market-based governance is insufficient for financial benchmarks subject to 'primary plus secondary use', hereinafter known as the 'regulable benchmark'. The Section also explains how and to what extent regulatory governance can fill in the governance deficit for such benchmarks.

\section{B. Balancing Regulatory and Market-based Governance- An Appropriate Approach to Governing Regulable Benchmarks}

The governance deficit in relation to the regulable benchmark can arise in two respects: one, in relation to the lack of policing against fraud or manipulation of the benchmark, and two in relation to the lack of assurance over the continued quality of the benchmark. Secondary users are interested in maintaining the integrity and credibility of the benchmark but they are unable to (a) detect or enforce against wrong-doing that damages the quality of the benchmark, ie ex post sanctions against those that have conducted damage to the benchmark; and (b) neither are they able to contribute to the ex ante processes that derive the benchmark.

Can it be argued that the first-mentioned governance deficit can be addressed by ex post private law actions and hence there is no real deficit that needs to be addressed? This article argues that private law regimes may not address free-rider/stakeholder grievances and hence the first-mentioned governance deficit exists as an 'enforcement deficit' where secondary users are concerned. Of course one can argue that there is no real enforcement deficit if secondary users have no right of expectations against benchmark producers to begin with. However, this argument is not satisfactory as it is merely formalistic, ignores the reality of secondary users as stakeholders and the real impact of the social utility of the benchmark upon market confidence in general. Nevertheless, existing

\footnotetext{
${ }^{24}$ Fair and Effective Markets Review, Recommendations on Additional Financial Benchmarks to Be Brought into UK Regulatory Scope (Report to HM Treasury, Aug 2014).

${ }^{25}$ Fair and Effective Markets Review, Recommendations on Additional Financial Benchmarks to Be Brought into UK Regulatory Scope (Report to HM Treasury, Aug 2014).

${ }^{26}$ http://fca.org.uk/news/fca-to-regulate-seven-additional-financial-benchmarks.
} 
private law sanctions may not cater for such secondary users as private law regimes are not set up for dealing with issues of interests that straddle the private and public spheres.

First, it is unlikely that secondary users of regulable benchmarks would be able to argue that benchmark producers owe them a duty of care in tort. Where financial benchmarks for price determination are concerned, there are benchmark submitters who convey quote or trade information, and who are primary users of the benchmarks themselves, and benchmark administrators who are aggregators or consolidators of such information and apply certain calculation processes to arrive at the benchmark for the relevant timeframe. The relational nexus exists between benchmark submitters and administrators. Thus, it would be challenging to argue that secondary users are owed a duty of care by either benchmark submitters or administrators. This would be different where a stock market index benchmark is concerned. Such index producers use proprietary methodologies to aggregate and process certain publicly available information in order to arrive at the benchmark for a determined group of licensed users. This set-up has a closed network of contractual relations as between the benchmark provider and licensed users only, and hence licensed users are likely to be able to seek redress in contract or tort actions where grievances arise.

The principles of tort law require a relationship of proximity between non-contractual parties for the forseeability of harm in order to impose a duty of care on such parties. ${ }^{27}$ Benchmark submitters are unlikely to foresee the scope of free-riders that would be affected by their submission of quotes or trade information. It may be argued that benchmark submitters could reasonably foresee that freeriding may take place, but the scope of persons who are likely to free-ride would be difficult to determine on an ex ante basis, or would simply be too large for the 'duty of care' mechanism to cope with. Further, individual benchmark submitters cannot be said to owe duties of care to freeriders as it would be impossible to foresee how individual submissions, which need to be aggregated, could affect the financial interests of any individual free-rider. Further, it could be argued that freeriders sign up for the variability of benchmark-linked price determination anyway and hence they should tolerate a margin of price uncertainty, and would find it hard to argue what financial losses they have incurred if benchmarks are not set optimally. Benchmark administrators are also unlikely to owe a duty of care to secondary users based on the unlikely prospect of establishing proximity with a wide and indeterminate scope of persons whose myriad financial interests are difficult to 'foresee'. It would also be difficult to impeach the processes benchmark administrators apply to aggregation and consolidation with a view to proving causation of loss to any individual secondary user.

Next, secondary users are unlikely able to seek redress in the private law regime of misrepresentation. Redress under misrepresentation is available to parties in a pre-contractual relationship, and free-riders are unlikely to be able to satisfy the relational aspects for misrepresentation actions. Primary users of financial benchmarks may be able to have redress in misrepresentation for grievances surrounding benchmark production. For example, companies that were sold interest rate swaps by the banks indicted in the LIBOR-rigging scandal could potentially

\footnotetext{
${ }^{27}$ Hedley Byrne \& Co Ltd v Heller \& Partners Ltd [1964] AC 465, Caparo Industries plc v Dickman [1990] UKHL 2. See generally leading textbooks on tort law, eg Mark Lunney and Ken Oliphant, Tort Law: Text and Materials ( $5^{\text {th }}$ ed, Oxford: OUP 2013) at chapter 3, pp120ff.
} 
make the banks contractually liable for misrepresentation. The manipulation of LIBOR carried out by one department of the bank could bring into question the appropriateness of using LIBOR as a price determination mechanism in such contracts, and a bank could be potentially impeached for misrepresenting the appropriateness of the financial benchmark as a price determining mechanism. ${ }^{28}$ However, where secondary users unrelated to the benchmark production processes use LIBOR to price their contracts, they have no interest in suing each other but would not be able to implicate benchmark producers who are beyond the parameters of the contract.

Even if the above hurdle in lack of contractual relations is overcome, it is arguable that benchmark submitters sending in quotes are sending in 'opinions' and hence not actionable as misrepresentations of fact, ${ }^{29}$ although there is case law to suggest that an opinion that is not honestly held can amount to a misrepresentation. ${ }^{30}$ Quotes could be treated as opinions if they are estimates made in response to a hypothetical question, such as 'At what rate could you ... accept inter-bank offers in a reasonable market size just prior to $11 \mathrm{am}$ ?' It could be argued that even if there is transactional data or similar data that allows the lender to come to a reasoned response, such a response is still an opinion and not likely to be actionable as misrepresentation. In a similar fashion, the treatment of credit rating agencies' ratings in private law is that they are opinions, although based on reasoned analyses of information. ${ }^{31}$

Moreover, as benchmark administrators have to aggregate and consolidate information, and processes such as a trimmed average is in place for quote-based submissions such as LIBOR (in order to mitigate the effect of outlying submissions), it would be difficult to allege what ultimately constitutes the 'misrepresented fact' upon which the free-rider is relying. Further, what window period of transactions would be regarded as affected and therefore compensable? It may also be argued that secondary users who benefit from the free-riding of financial benchmarks are unlikely the group of persons to incur the cost of private litigation, and also suffer from the collective action problem. Thus, the usefulness of private law remedies for such stakeholders would be rather remote. In sum, private law mechanisms are unlikely to address stakeholders' interest in enforcing against fraudulent or other damaging actions to a regulable benchmark.

Next, it is even less likely that secondary users would be able to influence the ex ante processes for quality assurance of a regulable benchmark as they are by nature free-riders that take the

\footnotetext{
28 'Barclays, Deutsche Bank Lose Bid to Halt U.K. Libor Suits', Bloomberg News (8 Nov 2013) but Barclays settled weeks before the trial, and hence the opportunity to discuss the legal duties in contract and tort was lost, see 'Barclays Settles U.K. Libor Case Weeks Before Start of Trial', Bloomberg News (8 Apr 2014). The case between Unitech and Deutsche Bank remains outstanding.

${ }^{29}$ Bisset v Wilkinson [1927] AC 177; Ball v Banner [2000] EGCS 36, where property advisers' opinions as to the profitability of certain lettings are not held to be actionable misrepresentations.

30 Smith v Land and House Property Corporation (1884) LR 28 Ch D 7; Esso Petroleum Co Ltd v Mardon [1976] QB 801.
}

${ }^{31}$ Amadou NR Sy, 'The Systemic Regulation of Credit Rating Agencies and Rated Markets' (June 2009) IMF Working Paper No 09/129 http://papers.ssrn.com/sol3/papers.cfm?abstract id=1426448. 
benchmark as it is. Existing market structures are unlikely to provide participatory avenues for secondary users to influence the production processes of a regulable benchmark.

However, can the governance deficits discussed above be addressed only by recourse to regulatory governance? Regulatory governance can often over-reach and it may be premature to dismiss the applicability of market-based governance. The regulable benchmark is a private market good to begin with and one should consider if there is still an appropriate role for market-based governance. This Section argues that there still needs to be a balance between regulatory governance and market-based governance in addressing the governance deficits of regulable benchmarks. This is because the regulable benchmark has not by reason of its governance deficits and therefore its need for a certain extent of regulatory governance, become a public good per se. Further, this Section will argue that regulatory governance needs to be based on a defined scope of public interest to be protected and market-based governance remains appropriate for certain aspects of benchmark governance.

The regulable benchmark caters for a useful purpose of price determination in longer term contracts with a variable price element. Its adoption by many does not make it an indispensable or regulable public good $^{32}$ as the public good characterisation brings about certain hazards. A public good characterisation of any financial benchmark may entrench a benchmark. A financial benchmark essentially serves private transactional needs and so its development should be tested in the market and subject to bottom-up affirmation of its quality and reliability. Regulatory endorsement could distort the natural processes in the market for testing benchmark quality. Further, the public good characterisation of a financial benchmark may truncate possibilities of innovation in the development of new and alternative benchmarks in the market for user choice. This Section is of the view that a public good characterisation of the regulable benchmark is inappropriate, as this may foreclose possibilities of achieving a balance between regulatory and market-based governance that best harnesses the social utility of the regulable benchmark.

Arguably, the public good that public authorities are interested in preserving is not the benchmark in question, but the benefits brought about by the adoption of that benchmark and the systemic implications from such widespread adoption. A widely-used benchmark reduces the transaction cost of price determination in incomplete contractual relationships and makes it cost-effective for many incomplete contractual relationships to be entered into in confidence. The widely-used benchmark promotes access to transactions and hence a form of democratisation of finance through transaction cost-reduction. The public good that therefore needs to be provided is the framework for transaction cost-reduction in order to supply avenues for democratisation of finance, and the maintenance of a form of stability in the widespread reliance upon such transaction-cost reduction frameworks.

\footnotetext{
${ }^{32} \mathrm{O}^{\prime} \mathrm{Brien}$ is of the view that widely used benchmarks have become public goods, and although this paper has much sympathy for the argument as it recognises the scale and systemic impact of widely used benchmarks, this paper is more cautious of the potential hazards for such a characterisation and therefore refrains from this. See Justin O'Brien, 'Singapore Sling: How Coercion May Cure the Hangover in Financial Benchmark Governance' (2013) at http://ssrn.com/abstract=2350445.
} 
Thus, the scope of regulatory governance should be based on (a) promoting the development of transaction-cost reduction devices; (b) ensuring that where a financial benchmark has attained a certain threshold of widespread and secondary use, its production should be appropriately accountable to primary and secondary users, and (c) selectively intervening only for the purposes of providing overall market stability in a crisis where widespread disruption or damage to secondary users' interest could result in a loss of market confidence and systemic instability. Regulators should maintain the balance of refraining from distorting the market for benchmarks by adopting or endorsing any financial benchmark and but also ensure that there is a strong hand to maintain market confidence and stability should there be a crisis related to secondary use. In sum, a balanced approach of proportionate regulatory governance and useful market-based governance would be the optimal framework to govern regulable benchmarks.

The next Section turns to explaining how an optimal regulatory regime can be designed and maps this analysis onto a critical comparison of the existing regulatory regimes.

\section{The Optimal Features of a Regulatory Framework for Regulable Benchmarks and Comparative Discussion of the Current Regulatory Regimes}

This article suggests that the appropriate extent of regulatory governance for regulable benchmarks should be a balanced one that optimally harnesses the positive attributes of market-based governance while addressing governance deficits that relate to the public goods that regulators are protecting: market confidence and stability. This Section suggests that regulatory governance should deal with: (a) the supply of public ex post sanctions where regulable benchmarks have been manipulated and (b) regulatory intervention in the attrition and transition of regulable benchmarks in 'crises'. It is suggested that regulatory governance should be more nuanced in dealing with ex ante governance frameworks for regulable benchmarks in view of concerns regarding market distortions and the inability of regulators to warrant benchmark quality anyway. This area is suggested to be left to a mixture of soft law and market-based governance. This would be different from the approach in current regulatory regimes and we will explain why.

\section{Regulatory Sanctions for Benchmark Manipulation}

As argued above, the public good that authorities are providing in relation to regulable benchmarks is that of a regulatory framework that supports transaction-cost reduction in order to democratise access to financial transactions, without entrenching particular benchmarks. Hence, such a regulatory framework should at a minimum seek to deter anti-social behaviour that is aimed at undermining the transaction-cost reduction devices that enjoy widespread stakeholder use, and to punish such behaviour in a socially visible manner if it occurs.

Anti-social behaviour such as manipulation of LIBOR by the submission of false or collusive quotes, or the manipulation of foreign exchange prices such as the London $4 \mathrm{pm}$ fix by collusive trading behaviour and information exchange ${ }^{33}$ are designed to benefit the few at the expense of damaging the social trust built up in the transaction-cost reduction devices of LIBOR and the WM Reuters 4pm fix. The undermining of social trust in widely-used financial benchmarks can result in significant

\footnotetext{
${ }^{33}$ See Martin DD Evans, 'Forex Trading and the WMR Fix' (2014) at http://papers.ssrn.com/sol3/papers.cfm?abstract_id=2487991.
} 
transaction costs for parties if price determination becomes much more complex and costly in the absence of a viable benchmark. Hence, anti-social behaviour that damages the quality and credibility of a widely-used benchmark can be subject to criminal and administrative penalties not because the benchmark as such is to be protected, but that there has been deliberate and unthinking undermining of the public good of a generally trusted and accepted transaction-cost reduction framework. On that basis, criminal and administrative penalties should be meted out to the rogue traders who have specifically engaged in benchmark manipulation. There may be a sliding scale of probity where many individuals may be implicated due to toxic organisational and sectoral culture. Hence, regulation should provide for the more severe punishments to be meted out for deliberate acts of manipulation, and acts of manipulation with reckless indifference as to consequences for the social profile and integrity of the benchmark. Less severe punishments may be meted out to persons who assist in the manipulation process as a result of lack of care, diligence or oversight. The social profile and importance of widely-used benchmarks would warrant an approach of strict liability for the organisations for whom the rogue traders are working. This deterrent effect could incentivise the management of such organisations to install systems and processes to prevent such behaviour, and to institute a proper culture.

The pursuit of wrong-doing individuals is necessary as some wrong-doers are deviants in an organisational set-up and therefore should be treated separately from the organisation concerned. In this respect, the UK Serious Fraud Office's prosecutions against bankers for LIBOR rigging ${ }^{34}$ are appropriate and on the right track. The pursuit of individuals should not be daunted by the prospect of a large scope of persons who may be indicted. Further, the UK financial regulator has powers to disqualify certain individuals from holding certain positions in a financial institution, and such disqualification powers, ${ }^{35}$ which have the effect of truncating a person's career and affecting his/her professional reputation, should provide some deterrent incentives.

As for large deterrent fines imposed on financial institutions for whom the rogue traders worked, this article is more sceptical of the size of fines levied. ${ }^{36}$ This article is of the view that organisations that have succumbed to toxic unethical cultures may benefit from such deterrent punishment to kickstart changes in organisational systems and culture. Many commentators ${ }^{37}$ have shed light on

\footnotetext{
34 'SFO secures first LIBOR guilty plea', Financial Times (7 Oct 2014); 'UK charges former Tullett Prebon employee over Libor rigging', Reuters (28 Oct 2014); and other prosecution actions against former bank employees mentioned in 'Further Charges in LIBOR Investigation', 17 Feb 2014 at http://www.sfo.gov.uk/press-room/latest-press-releases/press-releases-2014/further-charges-in-liborinvestigation.aspx that are ongoing.

${ }^{35}$ Section 66, UK Financial Services and Markets Act 2000.

36 'Big Banks Fined \$2.3B Over Illegal Libor Cartels, More Fines On The Way’, Forbes.com (4 Dec 2013); ‘Big Banks Slapped With f2.6bn FX 'Rate Rigging' Fines But Will They Ever Learn?', Forbes.com (15 Nov 2014).

${ }^{37}$ Anthony Salz, The Salz Review: An Independent Review of Barclays' Business Practices (April 2013); Jeanne L. Schroeder, 'Mad Money: Wall Street's Bonus Obsession' (2012) 33 Cardozo Law Review 2307; House of Lords and House of Commons, Changing Banking for Good (Report of the Parliamentary Commission on Banking Standards) (12 June 2013), 'Bankers have tendency to lie for financial gain, say scientists', Financial Times (20 Nov 2014) reporting on psychology research that shows how banking conditions individual behaviour to behave more dishonestly than one may be predisposed to.
} 
the toxic culture of the banking sector, especially where trading and investment are concerned. Santoro and Strauss argue that modern banking culture causes profit generation to become disengaged from the generation of social utility, ${ }^{38}$ and banking culture is characterised by high risktaking, individualistic behaviour, short-termism, blindness to stakeholders, and a lack of cooperation. Gapper $^{39}$ and Leadsom, ${ }^{40}$ writing in the Financial Times in the wake of the Barclays LIBOR fixing scandal of 2012, lament the selfish and unethical culture ${ }^{41}$ that has developed in contemporary banks, especially investment banks. However, one has to bear in mind that a number of the punished organisations have already begun programmes of cultural overhaul since the global financial crisis and the punishment should perhaps have taken into account of this when levying fines for historical wrongful behaviour. It is important to strike a balance between levying a financial penalty that is indisputably socially visible ${ }^{42}$ and incentivising constructive cultural change. Further, if organisations have reasonably sound systems of internal control but fail to detect the determined deviant, this article advocates that the individual deviant should be punished more spectacularly than the organisation, in which case, a smaller fine may be warranted for the organisation. In order to support organisations in detecting deviants, it is also important for regulators to encourage that financial institutions institute sound whistle-blowing policies, ${ }^{43}$ a point that has been taken up by most of the governance frameworks discussed below.

Next, we argue that it is inappropriate for regulatory governance to become too prescriptive about the quality of the benchmark as such. We will explain why market-based governance may play a significant role in this area, and also examine the current regulatory frameworks which have all taken a somewhat different approach.

\section{Design of an Ex Ante Governance Framework for the Quality of Regulable Benchmarks}

This article is sceptical of regulatory prescriptions that relate to the quality of any financial benchmark as these prescriptions may entrench certain benchmarks, inhibit future market innovation and distort the market for benchmarks (for example where benchmark incumbents engage in rent-extraction behaviour as their legitimacy is now protected by regulation and shielded from market competition). Users are likely to regard compliance as a proxy for benchmark quality and would not undertake efforts to determine for themselves if they are satisfied with the benchmark quality. This is due to users' behavioural bias towards seeking informational shortcuts

\footnotetext{
${ }^{38}$ Michael A Santoro and Ronald J Strauss, Wall Street Values: Business Ethics and the Global Financial Crisis (Cambridge: Cambridge University Press, 2012), chapter 5.

39 John Gapper, 'Trading Floor Culture no longer Acceptable' Financial Times (London, 5 July 2012).

${ }^{40}$ Andrea Leadsom, 'How an Old Hand would Change Barclays' Financial Times (London, 5 July 2012).

${ }^{41}$ See also Jerome Want, Corporate Cultures (NY: St Martin's Press, 2006).

${ }^{42}$ This aspect of deterrent punishment for financial institutions has been discussed in Philip Rawlings, Andromachi Georgosuli and Costanza Russo, 'Regulation of Financial Services: Aims and Methods' (2014) at http://www.ccls.qmul.ac.uk/docs/research/138683.pdf, pp.47ff, and it is queried if the extent of punishment has tended towards excessive severity.

${ }^{43}$ This area is under study for policy consideration, see reforms already accomplished in BIS, The Whistleblowing Framework: Call for Evidence (July 2013); Enterprise and Regulatory Reform Act 2013 amending section 43B of the Employment Rights Act 1996, sections $17 \mathrm{ff}$.
} 
and proxies, a behavioural heuristic known as 'satisficing'. Installing a regulatory framework for the ex ante governance of financial benchmarks is likely to reinforce blind user reliance.

At one end, regulatory governance could mean taking over the production of the benchmark altogether. This has been regarded as unwise by most commentators and is (rightly) not the approach in current regulatory regimes. A number of commentators opine that an optimal ex ante framework for benchmark production would not need to involve regulators in taking over the production of the benchmark. Kreicher et al ${ }^{44}$ have argued that users have long favoured private sector produced benchmarks over government ones as the latter are prone to instability when policy changes or macro-economic or political shocks occur.

The approach of current regulatory frameworks does not involve regulatory management of benchmark production but it involves regulatory prescription for benchmark administrators in terms of their governance, production processes and methodology. In this light, Verstein argues that ex ante forms of governance would only give rise to cosmetic compliance and unintended consequences that arise from unnecessary prescriptions, and it would be better to rely on robust ex post enforcement for fraud. ${ }^{45}$ This Section also argues that regulatory governance in this area should be a form of facilitative soft law in order to overcome some collective action problems, but should be proportionate in order not to over-reach into the quality of regulable benchmarks. The quality of regulable benchmarks is an area that can still be usefully developed subject to market-based governance. The design of such a facilitative soft law framework is supported by a user-centric perspective, as we shall discuss below.

\section{The (Secondary) User Perspective}

What do secondary user stakeholders legitimately expect of the quality of a widely-used benchmark? Arguably, they value others' trust in the benchmark, as widespread affirmation and endorsement of the benchmark provides the necessary comparability users need to make financial decisions. Hence, users' trust in a benchmark is not so much based on users being convinced themselves of the reliability of the benchmark or the qualities of benchmark submitters and administrators. Users' trust is based on the behavioural tendency towards herding in a collective or popular direction. Hence, ex ante governance frameworks designed to improve user scrutiny or accountability to users are unlikely to be effective. Moreover, the tendency towards herding behaviour by secondary user stakeholders is likely to engender a systemic consequence, i.e. widespread use and therefore systemic impact if the benchmark should fail or be severely impeached. Regulatory prescription in relation to benchmark quality will likely entrench users' blind reliance and herding behaviour, while not necessarily being able to guarantee benchmark quality. This article hence advocates caution in taking a prescriptive approach to governing benchmark production and prefers to explore avenues in soft law and market-based governance to encourage a race to the top in benchmark production.

\footnotetext{
${ }^{44}$ Lawrence Kreicher, Robert N McCauley and Philip Wooldridge, 'Benchmark Tipping in the Global Bond Market' (Oct 2014) at http://papers.ssrn.com/sol3/papers.cfm?abstract_id=2506748.

${ }^{45}$ Andrew Verstein, 'The Law and Economics of Benchmark Manipulation' (2015) 56 Boston College Law Review 3.
} 
The article argues that a soft law approach could be used in the design of an incentive-based framework to encourage benchmark producers to excel. Further, this framework should be supported by strong regulatory intervention if a crisis occurs in relation to a benchmark. A crisisbased intervention approach would ensure that there is a backstop to market confidence while not excessively interfering with the development of benchmark quality in normal times.

Further, a soft law framework that provides incentives for best practices in benchmark production to develop could entail a race to the top in regulatory competition. National financial markets can become deeper and more attractive if the use of financial benchmarks tied to these national markets is widespread even at the international level. The UK's interest in preserving the integrity of certain regulable benchmarks in connection with LIBOR, the London fix for foreign exchange or the London gold fix is tied to its interest in maintaining a dominant position for transactions based on these benchmarks that come to London markets. Hence, a facilitative form of regulatory governance could further the purpose of regulatory competition that supports national markets in their internationally competitive position.

It is suggested that the soft law framework for benchmark production should be adapted from the current regulatory regimes. In this light, this Section now turns to a comparative presentation of the UK regime for benchmark governance ${ }^{46}$ (instituted in the wake of the LIBOR scandal), the OICUIOSCO framework, ${ }^{47}$ the EBA-ESMA guidelines ${ }^{48}$ for the European Union and proposed legislation ${ }^{49}$ that is being debated in the EU. This Section will critically discuss the relevant features of the current regimes that should be adapted into a soft law framework in order to encourage an appropriate level of market-based governance.

\section{Comparative Discussion of Regulatory Governance of Benchmark Administration}

The current regulatory frameworks all adopt an approach whereby benchmark administrators are subject to rather extensive procedure-oriented regulation to ensure the robustness of their processes and their oversight of benchmark submitters. The Table below describes the obligations that benchmark administrators are subject to, including the institution of robust governance and internal control processes, the management of conflicts of interest, the institution of Codes of Conduct for benchmark submitters and oversight of benchmark submitters, the use of certain prescribed methodology in deriving the benchmark and reporting to regulators if not the public. This article is of the view that the governance frameworks for benchmark administrators are more or less prescriptive to a similar extent. As with much of procedure-oriented regulation, supervisory

\footnotetext{
${ }^{46}$ FCA Handbook MAR 8.

47 OICU and IOSCO, Principles for Financial Benchmarks: Final Report (July 2013).

${ }^{48}$ ESMA and EBA, Final Report: ESMA-EBA Principles for Benchmark-Setting Processes in the EU (June 2013).

${ }^{49}$ European Commission, Proposal for a Regulation of the European Parliament and of the Council on indices used as benchmarks in financial instruments and financial Contracts (21 Nov 2014, version Presidency compromise text).
} 
review $^{50}$ and oversight is necessary to ensure that the regulated engage in spirited compliance with the rules. However, this Section argues that much of the prescribed practices for benchmark administrators in governance and methodology are likely to impose significant cost upon benchmark administrators and it is queried to what extent benchmark quality is really achieved. Further, this Section argues that the approach of delegating significant oversight of benchmark submitters to benchmark administrators is misplaced and would fall short of the objective of the regulatory regime in ensuring that benchmark production fulfils the public good of transaction-cost reduction and maintenance of market stability.

Table for Comparison of the UK, IOSCO and EU approaches to regulating benchmark administrators:

\begin{tabular}{|c|c|c|c|}
\hline & UK FCA MAR 8 & OICU-IOSCO & $\begin{array}{l}\text { EBA/ESMA guidelines/ } \\
\text { proposed EU } \\
\text { legislation }\end{array}$ \\
\hline Governance structure & $\begin{array}{l}\text { Somewhat meta- } \\
\text { regulatory }{ }^{51} \text { in nature: } \\
\text { 'effective } \\
\text { organisational and } \\
\text { governance } \\
\text { arrangements' } \\
\text { Appointment of } \\
\text { benchmark } \\
\text { administration } \\
\text { manager responsible } \\
\text { for compliance } \\
\text { Regular review and } \\
\text { surveillance of quality } \\
\text { of benchmark } \\
\text { submissions } \\
\text { Institution of internal } \\
\text { whistle-blowing } \\
\text { procedures }\end{array}$ & $\begin{array}{l}\text { 'credible and } \\
\text { transparent } \\
\text { governance and } \\
\text { oversight' } \\
\text { Expertise of } \\
\text { benchmark } \\
\text { administrators } \\
\text { Institution of internal } \\
\text { control framework for } \\
\text { management of } \\
\text { conflicts of interest } \\
\text { and ensuring } \\
\text { compliance } \\
\text { Whistleblowing } \\
\text { framework } \\
\text { Internal control for } \\
\text { data collection }\end{array}$ & $\begin{array}{l}\text { 'effective governance } \\
\text { and compliance } \\
\text { processes to ensure } \\
\text { the quality of the } \\
\text { benchmark' } \\
\text { Appropriate criteria for } \\
\text { appointment of } \\
\text { members of governing } \\
\text { bodies or compliance } \\
\text { Internal control } \\
\text { mechanisms for } \\
\text { administrator, } \\
\text { submitters and other } \\
\text { third party outsources } \\
\text { Internal control over } \\
\text { quality of data } \\
\text { submitted } \\
\text { Whistle-blowing }\end{array}$ \\
\hline
\end{tabular}

${ }^{50}$ Cristie Ford, 'Principles-Based Securities Regulation in the Wake of the Global Financial Crisis' (2010) 55 McGill Law Journal 257; Cristie Ford, “New Governance, Compliance, and Principles-Based Securities Regulation" (2008) 45 American Business Law Journal 1.

${ }^{51}$ This means that the mode of regulation is worded widely in terms of outcomes to be achieved but the implementation of the procedures in firms that are needed to achieve the outcomes is delegated to the regulated. See Sharon Gilad, "It Runs in the Family: Meta-regulation and its Siblings" (2010) 4 Regulation and Governance 485; Cristie Ford, "New Governance, Compliance, and Principles-Based Securities Regulation" (2008) 45 American Business Law Journal 1; Cary Coglianese and David Lazer, "Management-Based Regulation: Prescribing Private Management to Achieve Public Goals" (2003) 37 Law and Society Review 691. 


\begin{tabular}{|c|c|c|c|}
\hline & & $\begin{array}{l}\text { Appointment of } \\
\text { internal or external } \\
\text { auditor who is } \\
\text { independent to } \\
\text { periodically report on } \\
\text { administrator's } \\
\text { compliance } \\
\text { Record keeping of all } \\
\text { data, submissions, } \\
\text { policies etc for } 5 \text { years }\end{array}$ & $\begin{array}{l}\text { procedures } \\
\text { Disciplinary procedures } \\
\text { Record keeping of all } \\
\text { oversight committee's } \\
\text { meetings with } \\
\text { administrator, third } \\
\text { parties etc for } 5 \text { years } \\
\text { Record keeping of all } \\
\text { data used for } \\
\text { benchmark calculation } \\
\text { to enable external } \\
\text { audit } \\
\text { Limitations on } \\
\text { outsourcing unless } \\
\text { adequate supervision } \\
\text { of outsourcees can be } \\
\text { put in place }\end{array}$ \\
\hline Governance principles & $\begin{array}{l}\text { Organisational and } \\
\text { governance } \\
\text { arrangements to } \\
\text { identify and manage } \\
\text { conflicts of interest } \\
\text { Ensuring } \\
\text { confidentiality of } \\
\text { benchmark } \\
\text { submissions }\end{array}$ & $\begin{array}{l}\text { Management of } \\
\text { conflicts of interest in } \\
\text { prescribed detail down } \\
\text { to staff reporting lines, } \\
\text { segregation of } \\
\text { responsibilities and } \\
\text { staff remuneration } \\
\text { Robustness of } \\
\text { operations such as } \\
\text { contingency measures } \\
\text { for failures in inputs or } \\
\text { markets or critical } \\
\text { functions }\end{array}$ & $\begin{array}{l}\text { Management of } \\
\text { conflicts of interest }\end{array}$ \\
\hline Accountability & $\begin{array}{l}\text { Institution of oversight } \\
\text { committee } \\
\text { represented by } \\
\text { submitters, markets } \\
\text { and non-executive } \\
\text { directors of the } \\
\text { administrator } \\
\text { Code of practice for } \\
\text { benchmark submitters }\end{array}$ & $\begin{array}{l}\text { Institution of } \\
\text { independent oversight } \\
\text { function to review } \\
\text { benchmark quality and } \\
\text { methodology, } \\
\text { outsourcing, } \\
\text { commissioning internal } \\
\text { or external audits } \\
\text { Oversight committee }\end{array}$ & $\begin{array}{l}\text { Oversight function or } \\
\text { committee } \\
\text { Committee has power } \\
\text { to directly report } \\
\text { irregularities to } \\
\text { regulator } \\
\text { Proposed Directive: } \\
\text { External audit }\end{array}$ \\
\hline
\end{tabular}




\begin{tabular}{|c|c|c|c|}
\hline & $\begin{array}{l}\text { Determining scope, } \\
\text { definition and } \\
\text { methodologies for } \\
\text { benchmark } \\
\text { Review of benchmark } \\
\text { submissions and } \\
\text { quality }\end{array}$ & $\begin{array}{l}\text { to also monitor for } \\
\text { benchmark } \\
\text { manipulation, code of } \\
\text { conduct for submitters }\end{array}$ & \\
\hline Methodology & None prescribed & $\begin{array}{l}\text { General principle of } \\
\text { 'accurate and reliable } \\
\text { representation of the } \\
\text { economic realities of } \\
\text { the Interest it seeks to } \\
\text { measure, and } \\
\text { eliminate factors that } \\
\text { might result in a } \\
\text { distortion of the price, } \\
\text { rate, index or value of } \\
\text { the Benchmark' } \\
\text { Data sufficiency } \\
\text { required, preference } \\
\text { for transaction-based } \\
\text { data in active markets, } \\
\text { that are bona fides, } \\
\text { arms-length } \\
\text { transactions. } \\
\text { Hierarchy of data input } \\
\text { to be constructed, with } \\
\text { preference for market } \\
\text { data above but } \\
\text { permitting quotes, bids } \\
\text { and offer data } \\
\text { Explicit setting out of } \\
\text { methodology for } \\
\text { calculation to be made } \\
\text { at least to } \\
\text { stakeholders, term } \\
\text { undefined }\end{array}$ & $\begin{array}{l}\text { General principle of } \\
\text { 'Benchmark should } \\
\text { represent adequately } \\
\text { the market, strategy or } \\
\text { interest to which it } \\
\text { refers, and measure } \\
\text { the performance of a } \\
\text { representative group } \\
\text { of underlyings in a } \\
\text { relevant and } \\
\text { appropriate way' } \\
\text { Methodologies must } \\
\text { be rigorous, systematic } \\
\text { and continuous, similar } \\
\text { to the regulation of } \\
\text { credit ratings quality } \\
\text { Preference for } \\
\text { transaction-based } \\
\text { data, permitting non- } \\
\text { transaction data } \\
\text { Proposed Directive: } \\
\text { safeguards needed } \\
\text { where input data is } \\
\text { mainly not transaction- } \\
\text { based data and any } \\
\text { submitter contributes } \\
\text { to more than } 50 \% \text { of } \\
\text { value of transactions in } \\
\text { market } \\
\text { Proposed Directive: }\end{array}$ \\
\hline
\end{tabular}

\footnotetext{
${ }^{52}$ Iris H-Y Chiu, 'Regulatory Governance of Credit Rating Agencies in the EU: The Perils of Pursuing the Holy Grail of Rating Accuracy' (2013) European Journal of Risk and Regulation 199.
} 


\begin{tabular}{|c|c|c|c|}
\hline & & & $\begin{array}{l}\text { Input data hierarchy to } \\
\text { be clearly established } \\
\text { Proposed Directive: } \\
\text { Expert judgment can } \\
\text { be used subject to } \\
\text { transparent and clear } \\
\text { guidelines } \\
\text { Methodologies to be } \\
\text { subject to regular } \\
\text { review } \\
\text { Methodologies subject } \\
\text { to public transparency }\end{array}$ \\
\hline $\begin{array}{l}\text { Oversight of third } \\
\text { parties }\end{array}$ & $\begin{array}{l}\text { Not explicit but can be } \\
\text { inferred from meta- } \\
\text { regulatory provisions } \\
\text { on effective } \\
\text { organisational and } \\
\text { governance } \\
\text { arrangements in order } \\
\text { to ensure due } \\
\text { administration and } \\
\text { publication of } \\
\text { benchmark }\end{array}$ & $\begin{array}{l}\text { Written policies and } \\
\text { procedures to manage } \\
\text { outsourced third } \\
\text { parties } \\
\text { Monitor third parties } \\
\text { for compliance } \\
\text { Contingency } \\
\text { arrangements if third } \\
\text { parties fail to deliver } \\
\text { Transparency of third } \\
\text { parties' identities to } \\
\text { relevant regulators and } \\
\text { stakeholders, term } \\
\text { undefined }\end{array}$ & $\begin{array}{l}\text { Proposed Directive: } \\
\text { Adequate supervision } \\
\text { of outsourcees } \\
\text { ESMA/EBA: Direct } \\
\text { guidelines addressed } \\
\text { to benchmark } \\
\text { calculation agents and } \\
\text { benchmark publishers } \\
\text { in terms of having } \\
\text { robust internal } \\
\text { governance for } \\
\text { compliance, conflicts } \\
\text { of interest } \\
\text { management, error } \\
\text { detection and } \\
\text { certification of } \\
\text { compliance to } \\
\text { administrator }\end{array}$ \\
\hline Transparency & Only to regulator & $\begin{array}{l}\text { To regulators, as per } \\
\text { below } \\
\text { To stakeholders, in } \\
\text { terms of benchmark } \\
\text { methodologies, third } \\
\text { party outsources, } \\
\text { conflicts of interest } \\
\text { and policies, and }\end{array}$ & $\begin{array}{l}\text { EBA/ESMA: Disclosure } \\
\text { of governance and } \\
\text { compliance committee } \\
\text { members to public } \\
\text { Disclosure of } \\
\text { benchmark } \\
\text { methodology to public } \\
\text { Proposed Directive: }\end{array}$ \\
\hline
\end{tabular}




\begin{tabular}{|c|c|c|c|}
\hline & & $\begin{array}{l}\text { transition policies for } \\
\text { benchmarks } \\
\text { Complaints procedure } \\
\text { for benefit of } \\
\text { stakeholders }\end{array}$ & $\begin{array}{l}\text { Transparency of } \\
\text { benchmark data } \\
\text { subject to Commission } \\
\text { delegated legislation } \\
\text { EBA/ESMA: } \\
\text { Certification of } \\
\text { compliance to public } \\
\text { EBA/ESMA: Complaints } \\
\text { procedures but } \\
\text { uncertain whether } \\
\text { internal or external } \\
\text { EBA/ESMA: Direct } \\
\text { guidelines addressed } \\
\text { to users viz users must } \\
\text { use sufficient due } \\
\text { diligence to ascertain } \\
\text { that all parties in the } \\
\text { benchmark production } \\
\text { processes comply with } \\
\text { guidelines; and that } \\
\text { users must regularly } \\
\text { assess the suitability } \\
\text { and relevance of a } \\
\text { benchmark }\end{array}$ \\
\hline $\begin{array}{l}\text { Relations with } \\
\text { regulator }\end{array}$ & $\begin{array}{l}\text { Notification to FCA of } \\
\text { suspected breaches by } \\
\text { administrator or } \\
\text { submitter } \\
\text { Notification to FCA of } \\
\text { suspected benchmark } \\
\text { manipulation } \\
\text { Reporting to FCA daily } \\
\text { on all benchmark } \\
\text { submissions } \\
\text { Providing FCA with } \\
\text { quarterly aggregate } \\
\text { statistics }\end{array}$ & $\begin{array}{l}\text { All documents and } \\
\text { audit trail to be } \\
\text { available to regulator } \\
\text { Disclosure of conflicts } \\
\text { of interest and policies }\end{array}$ & $\begin{array}{l}\text { Proposed Directive: } \\
\text { Registration system for } \\
\text { benchmark } \\
\text { administrators, } \\
\text { recognition of third } \\
\text { country administrators } \\
\text { based on equivalence } \\
\text { and allowing } \\
\text { registered } \\
\text { administrators to use } \\
\text { third country } \\
\text { benchmark based on } \\
\text { equivalent supervision } \\
\text { and arrangement in } \\
\text { place with ESMA. } \\
\text { Scrutiny over } \\
\text { benchmark }\end{array}$ \\
\hline
\end{tabular}




\begin{tabular}{|l|l|l|}
\hline |l| & & $\begin{array}{l}\text { methodology } \\
\text { EBA/ESMA: Scrutiny } \\
\text { over audit trail and } \\
\text { oversight committee's } \\
\text { meetings } \\
\text { EBA/ESMA: Reporting } \\
\text { of suspected } \\
\text { irregularities, Proposed } \\
\text { Directive will leave the } \\
\text { specifics to delegated } \\
\text { Commission legislation } \\
\text { EBA/ESMA: } \\
\text { Cooperation with } \\
\text { regulators over any } \\
\text { other query }\end{array}$ \\
& \\
&
\end{tabular}

At a global level, all three approaches ${ }^{53}$ have ramped up prescriptions for administrators' governance structures. The requirements to institute written policies, clear and transparent governance structures and procedures such as the oversight committee, internal control mechanisms, audit trails and irregularity detection mechanisms mean that existing benchmark administrators have to structurally overhaul their processes and practices, or that the opportunity may be taken for incumbent administrators to be challenged by re-tendering. The landscape of benchmark administration may change significantly especially at the conclusion of the UK Fair and Effective Markets Review in mid-2015. For example, the surrender of administration functions from existing institutions to other bodies may emerge, such as the ICE's triumph over the British Banking Association in taking over LIBOR administration. ${ }^{54} \mathrm{New}$ bodies such as exchanges like the ICE are well-placed to engage with benchmark administration as they naturally have transaction data and even pre-transaction data, and such is increasingly necessary to underpin benchmark production. Regulators however should beware the incentives that drive new bodies to take on relatively expensive benchmark administration. The emergence of bodies that may become systemically important due to their control over a significant benchmark or benchmarks must be considered. ICE has already gained administration rights over LIBOR, ISDAFIX and the LBMA Gold Fix. Further, ICE is generating revenues through licensing use, and this article queries if this is the effect intended to be achieved by regulators.

\footnotetext{
${ }^{53}$ The UK's somewhat minimalist approach may change in view of impending EU legislation and the reforms that the Fair and Effective Markets Review may recommend in mid 2015.

${ }^{54}$ ICE, Position Paper on the Evolution of ICE LIBOR (20 Oct 2014).
} 
Licensing use may unduly inhibit free access to a socially useful transaction-cost-reduction mechanism, which is the underlying public good regulators should protect. Nevertheless, it is noted that ICE does make historic LIBOR data available to the public 3 days late. ${ }^{55}$ However, allowing secondary user stakeholders to free-ride on delayed information still does not detract from the fact that preferential treatment is given to subscribers. It is queried if this unequal treatment would prejudice the retail market and allow financial institutions to further exploit secondary users as they would likely have an advantage in accessing current price information. The strengthening of governance structures comes at a cost and it is queried whether the unintended consequence of the new governance structures would be another form of undermining the secondary users' stake in having a reliable transaction-cost reduction mechanism! It is suggested that the regulator should monitor the impact of delayed publication to free-riders and consider whether the retail market is prejudiced in due course.

Further, concerns have been reported as to whether the cost of subscription to use financial benchmarks such as LIBOR may become too forbidding and cause primary users such as banks and financial institutions to move away from LIBOR. ${ }^{56}$ If so, the endeavours to strengthen the governance of benchmarks such as LIBOR, which inevitably impose cost, would ironically result in the instability of the benchmark as primary users defect. The rationale of benchmark regulation in order to protect secondary user stakeholders would be undermined by primary users' defection. The benchmark may become unstable and lose its comparable appeal from decreased use. The three current frameworks presented above have foreseen possible benchmark migration and instability and have put in measures to address those situations. However, this Section will shortly discuss the limitations in those measures especially in relation to distortions of healthy market forces. This problem highlights the difficulty in designing appropriate governance frameworks where market-based forces are dynamic.

It is also queried whether benchmark administrators who incur significant sunk costs in governance and methodology investments would become practically irremoveable. If so, we are exchanging one problem for another, i.e. in return for apparently fixing the reliability of benchmarks for widespread secondary use, we may install benchmark administrators who become too dominant, such that the social trust in such institutions could become a systemic risk issue. ${ }^{57}$ The importance of benchmark administrators would then demand greater supervisory scrutiny and dedication of regulatory resources to that. All three frameworks outlined above seem to agree on extensive supervisory powers on the part of the regulator to look into documents, practices, and subject benchmark administrators to supervisory review. In view of certain administrators' likely systemic impact, perhaps the UK FCA should undertakes $\mathrm{C} 1$ level review of such administrators, according to its

\footnotetext{
${ }^{55} \mathrm{https}: / /$ www.theice.com/marketdata/reports/170.

56 'Banks Mull Bailing on Libor in Loans as ICE Adds Licensing Fees', Bloomberg (14 Aug 2014).

${ }^{57}$ The UK FCA may already have forseen this in requiring all benchmark administrators to be subject to general principles of financial regulation such as the broadly worded PRIN fundamentals and the regulation of systems and governance (SYSC). See FCA Handbook BENCH 2.
} 
supervisory intensity framework. ${ }^{58}$ Further, it would be imperative to look into whether there are other actors in the regulatory space that could monitor benchmark administrators. The OICU-IOSCO and European authorities' guidelines also envisage stakeholder and public scrutiny, through mandatory disclosure of certain aspects such as benchmark production methodology and selected governance issues. Some commentators ${ }^{59}$ have queried whether public transparency is ideal as this allows room for benchmark submitters to collude more easily. ${ }^{60}$ This article also doubts that the secondary user base which carries out free-riding can be motivated to be diligent and act as monitors of benchmark administrators. This article is of the view that the current regulatory regimes could entrench benchmark administrators and there needs to be considered reflection on the needs of appropriate supervision and monitoring of such bodies in line with the regulatory expectations placed on them.

Further, the OICU-IOSCO and European initiatives make somewhat detailed prescriptions for the methodology in benchmark production. Although the UK approach is silent on such prescription at the moment, this approach would likely have to fall into line when European legislation comes into force ${ }^{61}$ Detailed prescriptions may run the risk of becoming out-dated, but this approach may be inevitable if the regulation of benchmark administrators ushers in a handful of entrenched and powerful benchmark administrators. Further, compliance costs will be incurred by benchmark administrators who have to conform to the prescribed practices. For example, the relatively low cost methodology in getting bank quotes for LIBOR submissions from a limited panel must give way to more sophisticated methods of combining wider panel bank quotes with real transaction data such as in overnight index swaps, repo markets etc. The investment in data collection and assimilation as well as methodological systems would be costly. The mandatory requirement to regularly review and perhaps back-test the credibility of benchmarks would also be costly. The cost implications reinforce the concerns suggested above regarding new administrator monopolies and limitations upon accessing the use of the benchmark by secondary users. Regulators need to revisit this tradeoff in due course to look into whether the benefits to secondary user stakeholders are compromised.

In view of the potential market distortion effects of regulating benchmark administration and the potential of adversely affecting the interests of secondary users, the protection of which motivated the introduction of regulatory governance to begin with, it is suggested that benchmark administrators should be subject to a more reflexive, soft law-type governance framework that

\footnotetext{
${ }^{58}$ FCA, Journey to the FCA (Oct 2012) at http://www.fsa.gov.uk/static/pubs/other/journey-to-the-fcastandard.pdf.

${ }^{59}$ Christoph Diehl, 'The LIBOR mechanism and Related Games' (2013) at http://ssrn.com/abstract=2289992; Rosa M. Abrantes-Metz and David S. Evans, 'Enhancing Financial Benchmarks: Comments on the OICU-IOSCO Consultation Report on Financial Benchmarks' (2013) at http://ssrn.com/abstract=2216209; Rosa M AbrantesMetz, 'Why and How Should the Libor be Reformed?' (2012) at http://ssrn.com/abstract=2094542.

${ }^{60}$ Although publication of granular quotes immediately after submission does not seem to the part of mandatory disclosure in all three approaches.

${ }^{61}$ European Commission, Proposal for a Regulation of the European Parliament and of the Council on indices used as benchmarks in financial instruments and financial Contracts (21 Nov 2014, version Presidency compromise text).
} 
encourages the adoption of best practices. This article suggests that regulators could set up a Code of Best Practice in relation to internal governance, control, structure and use of methodology by benchmark administrators. Adherence to the Code may provide a basis for regulators to award administration rights, which should be put out to tender on a competitive basis every 3-5 years. Such a system would prevent entrenchment of certain benchmark administrators and incentivise them towards best practices without making best practices a costly and compliance-based issue. The Code should also not prescribe detailed methodologies but could draw upon prevailing research by independent scholars ${ }^{62}$ and make recommendations which should be regularly revised.

This article further believes reflexive or soft law to be a more appropriate framework for benchmark administrators because not much would be achieved by regulatory enforcement against breach of regulatory requirements anyway. If administrators do a poor job and cause the credibility of a benchmark to be in doubt, enforcement action will likely reinforce the instability around the benchmark and damage secondary users' interests. Further, regulators may not be able to withdraw the administrator's licence in view of the impact on secondary users. In view of the lack of constructiveness of enforcement options, hard regulation may not achieve much and sacrifices the advantages of flexibility discussed above. Reflexive approaches would also mean that the relationship between regulators and administrators is structured not as a binary regulated-regulatee relationship but as a more cooperative relationship in governance partnership. ${ }^{63}$ This would likely reduce the burden of compliance cost for administrators and focus administrators towards the common good of producing socially useful benchmarks for transaction-cost reduction in the market.

It may be argued that the potential rotation of benchmark administrators would be contrary to regulatory expectations placed on them to oversee benchmark submitters. However, this article argues that benchmark administrators should not have the primary burden of overseeing benchmark submitters at all. Under the current regulatory regimes, as benchmark submitters voluntarily provide information to administrators for the production of the benchmark, it would be difficult to subject submitters to regulation without making submission mandatory. Mandatory submission would subvert the production of the private market good for transaction cost reduction, and regulators possibly do not wish to go as far as recalibrating regulable benchmarks as public goods. Hence, it seemed inevitable that benchmark administrators would be best placed to oversee the voluntary administrator-submitter relationship. As such the current regulatory regimes attempt to regulate administrators extensively while incentivising them to oversee submitters, taking the soft law approach where submitters are concerned.

\footnotetext{
${ }^{62}$ Darrell Duffie and Jeremy C Stein, 'Reforming LIBOR and Other Financial-Market Benchmarks' (2014) at http://ssrn.com/abstract=2506792 on use of a wider range of transaction data; Alexander Eisl Rainer Jankowitsch and Marti G. Subrahmanyam, 'The Manipulation Potential of Libor and Euribor' (2014) at http://ssrn.com/abstract=2201013 on enlarging panel size and use of a trimmed median method; Rosa M. Abrantes-Metz and David S. Evans, 'Enhancing Financial Benchmarks: Comments on the OICU-IOSCO Consultation Report on Financial Benchmarks' (2013) at http://ssrn.com/abstract=2216209 with similar recommendations to above.

${ }^{63}$ The smart regulation model, see Neil Gunningham, Peter Grabosky and Darren Sinclair, Smart Regulation: Designing Environmental Policy (Oxford: OUP 2004).
} 
This article will argue that the soft law approach for submitters is not preferred. In order to harness the optimal mix of regulatory and market-based governance, this article suggests the opposite approach, i.e. to rely on more soft law and market-based governance for benchmark administrators, and to provide regulatory governance over benchmark submitters instead. The below will present the three current regulatory approaches to benchmark submission and will critically discuss the limitations of current approaches and suggest an alternative way forward.

\section{Comparative Discussion of Regulatory Governance of Benchmark Submission}

The UK, IOSCO and EBA-ESMA have all designed a procedure-oriented framework for submitters but direct regulatory oversight is much more limited. The Table below presents the three current regulatory approaches with broad similarities and minor differences. The key commonality in all three approaches outlined above is that benchmark submitters are governed and overseen by benchmark administrators instead of regulators. This is because benchmark submission is a voluntary activity and extending regulatory reach over it could at this time be regarded as excessive. Regulators may wish at the moment to avoid having to go as far as instituting a new system of mandatorising benchmark submission. However, it will be argued that this approach is counterproductive to the rationales for governing regulable benchmarks. Further, delegating oversight of benchmark submitters to administrators makes benchmark administration more costly and enforcement deficit is also very likely. Such enforcement deficit raises real and serious concerns as benchmark manipulation is carried out much more extensively at submitter level rather than at administrator level. Hence, the current regulatory approaches of subjecting benchmark submitters to administrators' oversight are likely contrary to achieving protection for secondary users/stakeholders.

\begin{tabular}{|c|c|c|c|}
\hline & UK FCA & OICU-IOSCO & $\begin{array}{l}\text { EBA/ESMA guidelines } \\
\text { and EU legislation }\end{array}$ \\
\hline Governance structure & $\begin{array}{l}\text { 'effective } \\
\text { organisational and } \\
\text { governance } \\
\text { arrangements' } \\
\text { Appointment of } \\
\text { benchmark manager to } \\
\text { ensure compliance } \\
\text { Responsibility for } \\
\text { oversight of } \\
\text { benchmark submission } \\
\text { to reside with senior } \\
\text { personnel } \\
\text { Benchmark submitter } \\
\text { to be based on UK } \\
\text { Record keeping of }\end{array}$ & $\begin{array}{l}\text { Internal systems and } \\
\text { controls to deal with } \\
\text {-management of } \\
\text { conflicts of interest } \\
\text {-application of } \\
\text { methodology } \\
\text {-pre-submission } \\
\text { validation by senior } \\
\text { personnel } \\
\text {-internal sign-off } \\
\text { procedures for } \\
\text { submission } \\
\text {-whistleblowing } \\
\text { policies }\end{array}$ & $\begin{array}{l}\text { Clear internal policies } \\
\text { developed for } \\
\text { submissions, internal } \\
\text { control, training, } \\
\text { record-keeping, } \\
\text { compliance, internal } \\
\text { audit, disciplinary } \\
\text { procedures, } \\
\text { complaints } \\
\text { management and } \\
\text { escalation } \\
\text { Effective } \\
\text { organisational and } \\
\text { administrative } \\
\text { arrangements to } \\
\text { manage conflicts of } \\
\text { interest, highly }\end{array}$ \\
\hline
\end{tabular}




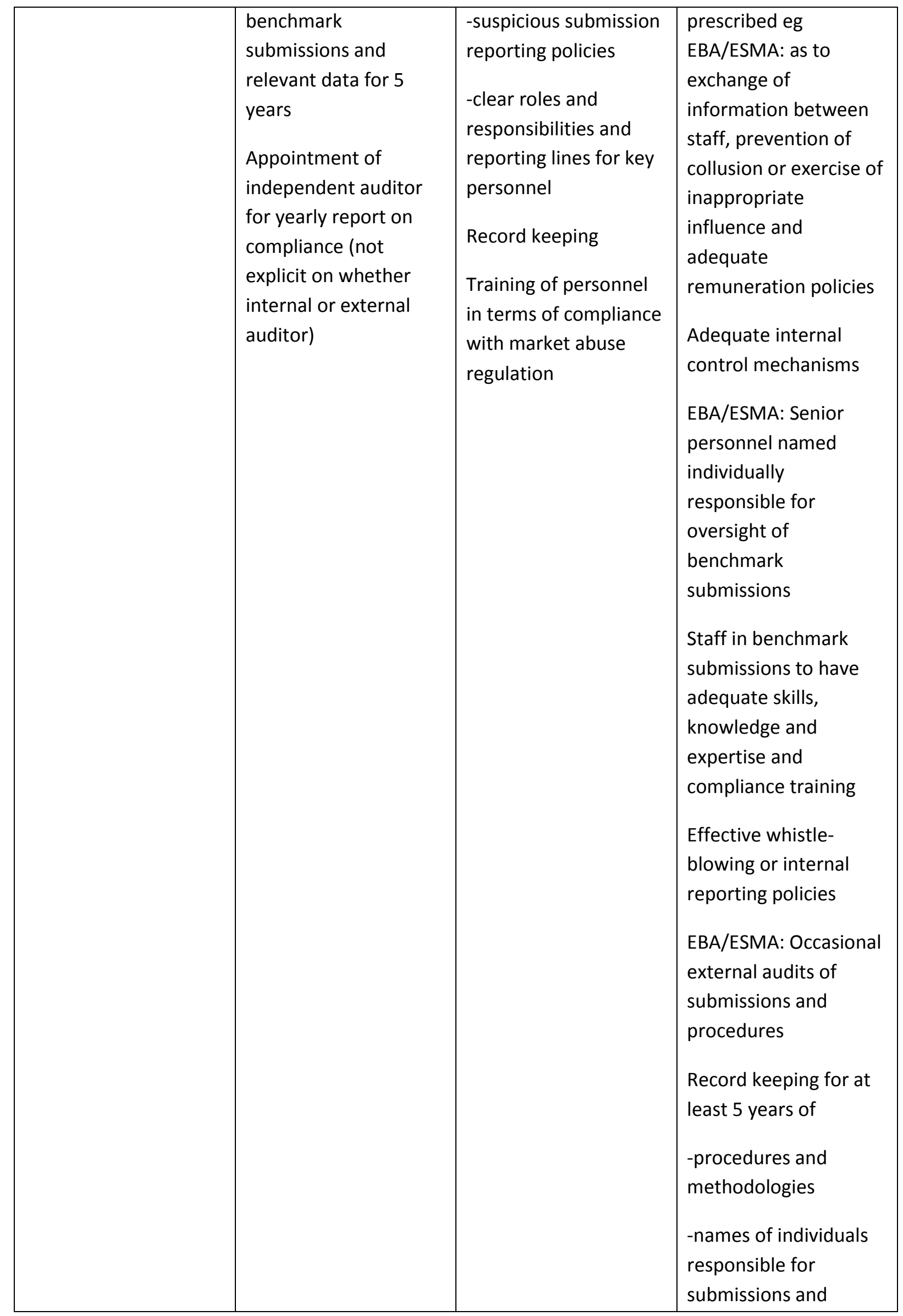




\begin{tabular}{|c|c|c|c|}
\hline & & & $\begin{array}{l}\text { oversight } \\
\text {-communications with } \\
\text { benchmark } \\
\text { administrators or other } \\
\text { third parties } \\
\text {-substantial exposures } \\
\text { of individual traders or } \\
\text { trading desks to } \\
\text { Benchmark related } \\
\text { instruments; } \\
\text { - any transaction } \\
\text { reversing positions } \\
\text { subsequent to a } \\
\text { submission; } \\
\text { - findings of external } \\
\text { or internal audits } \\
\text { related to Benchmark } \\
\text { submission, remedial } \\
\text { actions and progress in } \\
\text { their implementation } \\
\text { Note Proposed } \\
\text { Directive is more } \\
\text { skeletal and leaves } \\
\text { details to Commission } \\
\text { delegated legislation }\end{array}$ \\
\hline Governance principles & $\begin{array}{l}\text { Management of } \\
\text { conflicts of interest by } \\
\text { written policy } \\
\text { Rigorous detection and } \\
\text { reporting of suspected } \\
\text { manipulation and } \\
\text { collusion }\end{array}$ & $\begin{array}{l}\text { Management of } \\
\text { conflicts of interest } \\
\text { Robust procedural } \\
\text { internal control culture }\end{array}$ & $\begin{array}{l}\text { Management of } \\
\text { conflicts of interest } \\
\text { EBA/ESMA: zero- } \\
\text { tolerance policy, } \\
\text { including disciplinary } \\
\text { measures, for non- } \\
\text { compliance with } \\
\text { internal policies }\end{array}$ \\
\hline $\begin{array}{l}\text { Duties of benchmark } \\
\text { submitter }\end{array}$ & $\begin{array}{l}\text { Ensuring that } \\
\text { benchmark } \\
\text { submissions are } \\
\text { credible and robust }\end{array}$ & $\begin{array}{l}\text { In a Code that would } \\
\text { be drawn up by } \\
\text { benchmark } \\
\text { administrator }\end{array}$ & $\begin{array}{l}\text { ESMA/EBA: } \\
\text { Compliance-based, to } \\
\text { certify to benchmark } \\
\text { administrator }\end{array}$ \\
\hline Methodology & $\begin{array}{l}\text { Effective methodology } \\
\text { based on objective }\end{array}$ & $\begin{array}{l}\text { Processes to } \\
\text { determine input }\end{array}$ & $\begin{array}{l}\text { Transaction-based } \\
\text { verifiable data to be }\end{array}$ \\
\hline
\end{tabular}




\begin{tabular}{|c|c|c|c|}
\hline & $\begin{array}{l}\text { criteria and relevant } \\
\text { information } \\
\text { Qualitative criteria } \\
\text { allowed such as expert } \\
\text { judgment } \\
\text { Review at least every } \\
\text { quarter for robustness } \\
\text { and credibility of } \\
\text { methodology }\end{array}$ & $\begin{array}{l}\text { eligibility } \\
\text { Bona fides of input } \\
\text { important criteria } \\
\text { Expert judgment can } \\
\text { be used }\end{array}$ & $\begin{array}{l}\text { used } \\
\text { Other input or } \\
\text { qualitative judgment } \\
\text { can only be used } \\
\text { subject to internal } \\
\text { control and guidelines } \\
\text { eg: EBA/ESMA: with } \\
\text { senior personnel } \\
\text { approval }\end{array}$ \\
\hline Accountability & $\begin{array}{l}\text { Information on } \\
\text { methodology and use } \\
\text { of quantitative and } \\
\text { qualitative criteria to } \\
\text { be sent regularly to } \\
\text { benchmark } \\
\text { administrator } \\
\text { Notification of } \\
\text { suspected } \\
\text { manipulation or } \\
\text { collusion to FCA } \\
\text { Independent auditor } \\
\text { for yearly report on } \\
\text { compliance to be sent } \\
\text { to FCA }\end{array}$ & $\begin{array}{l}\text { To benchmark } \\
\text { administrator based on } \\
\text { Code of Conduct } \\
\text { Unclear as to where } \\
\text { notification of } \\
\text { suspicious activity goes }\end{array}$ & $\begin{array}{l}\text { To benchmark } \\
\text { administrator based on } \\
\text { Code of Conduct, } \\
\text { Proposed Directive: } \\
\text { Code to be approved } \\
\text { by regulator for critical } \\
\text { benchmarks } \\
\text { ESMA/EBA: To respond } \\
\text { to regulator if } \\
\text { regulator makes } \\
\text { queries directed at } \\
\text { submitter }\end{array}$ \\
\hline $\begin{array}{l}\text { Relations with } \\
\text { regulator }\end{array}$ & $\begin{array}{l}\text { Unclear whether FCA } \\
\text { has direct enforcement } \\
\text { powers and in what } \\
\text { form } \\
\text { Unclear whether FCA } \\
\text { has powers to directly } \\
\text { investigate and call up } \\
\text { documents but this } \\
\text { may be subsumed } \\
\text { within general powers } \\
\text { FCA has under the } \\
\text { Financial Services and } \\
\text { Markets Act } 2000\end{array}$ & $\begin{array}{l}\text { Unclear if there are } \\
\text { any direct relations }\end{array}$ & $\begin{array}{l}\text { ESMA/EBA: To respond } \\
\text { to reasonable queries } \\
\text { from regulator }\end{array}$ \\
\hline
\end{tabular}


All three current regulatory regimes prescribe that benchmark submission should be subject to robust internal governance and control frameworks in firms, as well as to management of conflicts of interest, with the EU guidelines and proposed legislation going into the greatest amount of prescriptive detail. However it remains uncertain what the accountability channels for benchmark

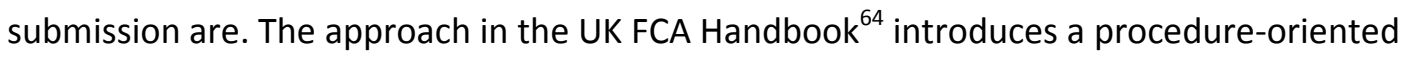
framework to prescribe aspects of governance structures, principles and benchmark submission methodology, but at the same time, benchmark administrators are to develop a Code of Practice Standards for submitters. ${ }^{65}$ The FCA has general powers to carry out supervision and enforcement against the subjects of its regulation, and this may suggest that the FCA has direct enforcement powers against benchmark submitters who are subject to the prescriptions in the Handbook. But it is unclear if administrators have primary disciplinary jurisdiction over submitters and whether there is an overlap between the FCA and administrators in disciplinary jurisdiction over submitters. The OICU-IOSCO and EU frameworks are clearer that regulators have limited jurisdiction over benchmark submitters, although the regulator is expected to have oversight of the administrator's Code for submitters where 'critical benchmarks' ${ }^{66}$ are concerned. Direct regulatory governance of benchmark submitters may be argued to be untenable, as benchmark submission is up to voluntary participation. Such participation, unlike benchmark administration, is not susceptible of being a regulated activity ${ }^{67}$ as the extension of regulatory governance to benchmark submission would just compel submitters to stop submitting in order to avoid compliance costs. This is counter-productive to the reliability of the benchmark as larger panels of submission are empirically proved to relate to more robust benchmarks. ${ }^{68}$ The three frameworks above are limited in being able to address the issue of governance at the submitter level. It seems that the comparatively extensive regulation of administrators may be designed to mitigate this particular aspect of impotence. However, this Section will shortly argue that the direct regulation of benchmark submitters is in fact necessary and will make recommendations to reconcile voluntary aspects of market activity such as benchmark submission with regulation.

Further, this Section argues that it is ineffectual to require benchmark administrators to draw up a Code for submitters and oversee compliance with the Code. Oversight of benchmark submitters

\footnotetext{
${ }^{64}$ MAR 8.2.

${ }^{65}$ MAR 8.3.10.

${ }^{66}$ Defined as being dependent on the value of financial contracts and transactions that reference the benchmark, at least 500bn euros and above, and the impact on market stability should the benchmark be discontinued or become unreliable.

${ }^{67}$ Section 22(1A) of the Financial Services and Markets Act 2000 as amended by the Financial Services Act 2012 specifies that activity carried on by way of business relating to the setting of a benchmark' is regulated activity. That argubly covers benchmark administrators who finally set the benchmark and not benchmark submitters who contribute data. Further contributions of data may not be carried out 'in the course of business'. The Explanatory Notes to Clause 7 of the Financial Services Bill 2012 does not clarify, see http://www.publications.parliament.uk/pa/bills/cbill/2012-2013/0002/en/2013002en.htm.
}

\footnotetext{
${ }^{68}$ Alexander Eisl Rainer Jankowitsch and Marti G. Subrahmanyam, 'The Manipulation Potential of Libor and
} Euribor' (2014) at http://ssrn.com/abstract=2201013. 
adds cost to benchmark administration, and it would be easy to rely on box-ticking for cosmetic compliance to demonstrate that administrators have discharged oversight. Moreover, what incentives do benchmark administrators have in taking disciplinary enforcement against benchmark submitters? If there is a procedural issue such as having a less-than-optimal written policy in management of conflicts of interest, would benchmark administrators undertake the hassle and cost of disciplining submitters and risk losing their voluntary participation? If there is a case of suspected manipulation, this would likely be dealt with at the regulator and not administrator level.

This next Section discusses the alternative approach suggested in this article- the direct regulation of benchmark submission which would not undermine participation in submission activity. Further, this article will also propose reforms to deal with the issue of ensuring market stability if a benchmark becomes reputationally damaged or unstable due to insufficient support for its production and/or if new benchmarks arise in the market. The issue of transition from the disuse of certain benchmarks has only been addressed cursorily by the three regulatory frameworks discussed above.

\section{The Regulation of Benchmark Submission}

This article proposes that instead of viewing benchmark submission as an isolated and voluntary activity, regulators should look at benchmark submission as part of the wider context of financial intermediation activities and design an appropriate scheme of regulatory governance based on a wider notion of 'benchmark participation'. 'Benchmark participation' should be defined widely to mean any activity including the entering into of bilateral transactions that involves using a mechanism to determine price that is not merely based on the firm's proprietary formulae. Hence, a bank or financial institution should be subject to regulatory governance based on the use of a market mechanism to determine price in any financial instrument or transaction entered into by the institution concerned, whether or not the institution participates in the setting of the market mechanism. This scope would include primary users who are actual benchmark submitters or otherwise, and all would be regarded as being involved in 'benchmark participation'. Such a scope is necessary so as to capture a drifting net of submitters and to put an end to the potential cat-andmouse game of benchmark defection by voluntarily participating primary users looking to evade regulation. It would render benchmark defection for the purpose of evading regulation redundant. Such a scope ensures that the majority of primary users, which are banks and financial institutions, are captured within the scheme of governance.

This article argues that benchmark participating activity should be governed by a set of principles that falls within the firms' existing regulatory obligations in internal control and treating customers fairly. ${ }^{69}$ In other words, the fundamental rubric of prudential and conduct regulation for the financial sector would also encompass benchmark participation, making this activity subject to the same broad regime of existing regulation. This article believes that such a framework achieves more coherence and comprehensiveness in regulating regulable benchmarks. First, it is proposed that banks and financial institutions should ensure that benchmark-related activity is subject to internal control, hence falling in line with existing prudential regulation. Second, banks and financial institutions should also be subject to regulatory principles of ensuring customer fairness where benchmark participation activity is concerned, consistent with existing conduct regulation.

\footnotetext{
${ }^{69}$ Principles 3 and 6, FCA Handbook, PRIN module.
} 
Supervisory scrutiny is essential for ensuring that the regulatory principles are implemented effectively. ${ }^{70}$

In relation to the first aspect, this article suggests that benchmark participaters should ensure that the use and adoption of any benchmark is part of rigorous internal control. ${ }^{71}$ This means that a regulatory duty should be imposed on firms in that regard, and benchmark participaters should be satisfied about the integrity, credibility and adequate continuity of the benchmark, in order to protect transactional integrity of the firm's exposures, and hence protect the firm from financial risks. At the very least, the firms' internal control functions should be empowered to critically scrutinise benchmarks adopted in transactions. Where the firm is also a participater in terms of submission activities, ie contributing data or quotes or other information to assist in setting the benchmark, then the firm must ensure that submission activities are carried out within a robust internal control framework and culture to protect the firm and to undermine risks to counterparties. If insufficient internal control is applied to benchmark submission activities, such a firm may be regarded as falling short of adequate internal control obligations and may attract prudential-type sanctions such as capital charges. ${ }^{72}$

Further, the obligation imposed on firms to ensure that their benchmark participation is subject to adequate internal control may also be regarded as having an effect upon how the firm treats customers. If the firm fails to exercise due internal control in its benchmark participation activities, including submission activities, such failure could be regarded as falling short of the 'treating customers fairly' principle, as the use of such benchmarks in retail transactions could be prejudicial to customers' interests. The 'treating customers fairly' principle, although worded widely, has been held to be capable of giving rise to discrete enforcement actions by regulators and is regarded as the 'fundamental regulatory obligation' upon which more precise rules may be based. ${ }^{73}$ Its lack of specific prescription has not prevented courts from enforcing protection intended in this principle for aggrieved customers of financial institutions. ${ }^{74}$

It is argued that such a regulatory design incorporates benchmark use and submission into the existing regulatory framework for supervising banks' and financial institutions' internal control and customer-facing responsibilities, thus extending the regulatory scheme in a cost-effective and justifiable manner while not being held hostage to a drifting net of voluntary benchmark submitters.

\footnotetext{
${ }^{70}$ Above.

${ }^{71}$ Which is now subject to enhanced regulation post-global financial crisis 2008-9, and the subject of detailed study in Iris H-Y Chiu, Regulating from the Inside: The Legal Framework for Internal Control in Banks and Financial Institutions (Oxford: Hart 2015), forthcoming.

72 These can be levied under Pillar 2A of the UK Prudential Regulation Authority's framework, see Bank of England, The PRA's Approach to Banking Supervision (Oct 2012) at 25, see http://www.fsa.gov.uk/static/pubs/other/pra-approach-banking.pdf.

${ }^{73} R$ v FSA \& FOS ex p BBA \& one other [2011] EWHC 999 (Admin). See also Andromachi Georgosuli, 'The FSA's 'Treating Customers Fairly' (TCF) Initiative: What is so good about it and why it may not work' (2011) .Journal of Law and Society 405.

${ }^{74}$ Above.
} 
It is also argued that regulatory focus should be placed at the benchmark participation/submission level as it is the primary level activities carried out by banks and financial institutions that have given rise to concerns in the recent LIBOR, foreign exchange fixing and gold-fixing scandals. It does not seem appropriate that the three regulatory schemes discussed earlier preponderantly focus on the benchmark administrators and expect for-profit administrators to oversee benchmark submitters effectively. Further, the proposed regulatory design is likely to dis-incentivise benchmark defection for the purposes of merely evading a benchmark subject to regulation, a problem that the current regulatory regimes have not satisfactorily addressed. The subjection of all financial institution benchmark users to the same governance framework ensures that there is less disparity in cost implications for submitters and users in the wholesale market. Moreover, primary users would indeed prefer and possibly take the initiative to foster benchmark credibility and continuity as part of good risk management and internal control. The proposed regulatory design may more effectively harness incentives on the part of the wholesale market to maintain the continuity of established benchmarks, and this benefits secondary user stakeholders.

The proposed regulatory design above also addresses the issues fleshed out earlier concerning excessive cost imposed on administrators which would only entail the adoption of revenuegenerating methods that undermine secondary user stakeholders. The direct regulatory governance extended over benchmark participation activities is proportionate and falls within the remit of the UK regulator. It is arguably cost-effective for the regulator and for administrators who should focus on their area of expertise in collating and aggregating data in order to produce the benchmark. In sum, regulatory governance would be strengthened directly vis a vis banks and financial institutions in terms of their benchmark participation activities. Secondary users' interest in the credibility of a widely-used benchmark would be secured by leveraging upon the existing enforcement regimes for prudential and conduct regulation, as well as the new criminal sanctions for benchmark manipulation.

\section{The Role of Regulatory Governance in Benchmark Crises}

Finally, this article suggests that regulatory governance could play a dominant role where there is a benchmark crisis. The three current regimes all allude to the possibility of benchmark crises but provide rather minimal guidance on the management of the attrition and transition of benchmarks. This Section argues that there is a need to introduce regulatory governance to address this issue. This is because a benchmark crisis that has an adverse impact on market stability could best be addressed by regulatory intervention and not market-based mechanisms. Market-based mechanisms are likely to succumb to collective action problems and are unlikely to achieve a coordinated response that would be needed to address adversities in market confidence. ${ }^{75}$

The UK FCA Handbook requires that benchmark administrators take into account of the need to maintain 'continuity of the specified benchmark including the need for contractual certainty for contracts which reference the specified benchmark ${ }^{76}$ as part of their administration responsibilities.

\footnotetext{
${ }^{75}$ See Steven Schwarcz, 'Systemic Risk' (2008) 97 Georgetown Law Journal 194 discussing the nature of system-wide problems such as the materialisation of systemic risk and why market-based mechanisms will likely fail to address the materialisation of those risks.

${ }^{76}$ MAR 8.3.2.
} 
Without specific guidance, is this a mandate to entrench a benchmark? Or to come to arrangements with submitters so that participation is not truncated abruptly? Or is this a mandate to take leadership in designing standard transition clauses in contracts so that benchmark problems would not affect ultimate price determination? The UK regime is not thoroughly clear on what administrators are expected to achieve in respect of benchmark continuity. The OICU-IOSCO guidelines are more prescriptive but place the responsibility on administrators to have written policies in place relating to transition, and to exhort users to prepare for benchmark transitions. ${ }^{77}$ The European guidelines try to avoid benchmark discontinuity by recommending that administrators encourage submitters not to withdraw and that their publicly disclosed methodologies must incorporate considerations for operational continuity. ${ }^{78}$ The proposed European legislation continues along similar lines by mandating ESMA to review critical benchmarks every 4 years and by providing for national regulators the power to force mandatory benchmark submissions during benchmark transitions. ${ }^{79}$ The issue of benchmark attrition, transition and emergence of new benchmarks is part of parcel of market-based forces and market innovation, and regulators should be cautious as to unintended consequences that arise from regulatory interventions.

The existing frameworks do not satisfactorily address the need to mitigate disruptive impact if benchmarks have to be replaced. Although the current regimes make administrators responsible for the continuity of benchmarks as far as is possible, there is little guidance on either the ex ante actions administrators should take, or the ex post measures administrators should have in place should a regulated benchmark indeed becomes unstable. Further, imposing a duty on administrators to ensure benchmark continuity does not provide the right incentives for administrators to develop a satisfactory solution. It would be futile for regulators to carry out enforcement action against administrators if a market crisis of confidence indeed occurs. This article also argues that imposing a duty on administrators to ensure benchmark continuity would entrench existing benchmarks and entail neglect for the need to encourage innovation in the market for effective benchmark production. Finally, this article is of the view that in a crisis of confidence regarding a widely-used benchmark, market stability is at stake and the responsibility for managing the situation of a damaged benchmark or a benchmark in transition should not and cannot merely lie with benchmark administrators which are for-profit private sector bodies. Administrators' expertise should lie in the robust collation and aggregation of data to produce a benchmark, and such expertise does not necessarily lend itself to the existence of a governance expertise or capacity. Just as this article is of the view that it is costly to delegate oversight of benchmark submitters to administrators, it is even more remote and implausible to ask administrators to put in place governance structures to protect secondary user interests in the continuity of benchmarks.

Further, the attempt to prevent benchmark attrition by compelling benchmark submission, such as envisaged under the European framework, may be futile and market-distorting. Such a framework fails to see the prospects of benchmark innovation and merely encourages steps to preserve the status quo where market confidence has tumbled.

\footnotetext{
${ }^{77}$ Principle 13.

${ }^{78}$ Paras B. 2 and B.5.

${ }^{79}$ Other transitional policies may be further developed by ESMA in Commission delegated legislation.
} 
This article argues that the issue of maintenance of market stability where a benchmark crisis has occurred should prima facie be one of regulatory interest which for-profit administrators may not be best placed to govern. Overseeing benchmark attrition and transition is arguably a form of crisis management which regulators are best placed to do in securing the public interest of market stability. Hence, this Section argues that regulatory governance should more clearly be extended to manage episodes of benchmark instability or transition.

It is therefore suggested that regulators should be prepared to take over the temporary administration of a benchmark if a major benchmark becomes impeached or damaged, in order to regulate transitional matters for myriad transactions. This provides confidence and certainty for transactions, protects secondary user stakeholders and allows regulators to exercise necessary powers to achieve the wider interest of market stability. However this power should be applied sparingly, such as where a regulable benchmark becomes impaired and where widespread implications in the market have resulted. This suggestion is unlikely out of line with the trend of developing regulator-managed paradigms for financial crisis management and resolution of financial institutions, as has come into place in the US, ${ }^{80}$ Europe $^{81}$ and UK. ${ }^{82}$

Besides crisis-management powers for regulators, this article also proposes that regulators should put in place guidelines for orderly benchmark transition if it occurs. Such a framework can be based on protecting customers and secondary users. As benchmark transition will affect transactions at a bilateral level, regulators should not assume over-riding powers to rewrite contracts. Regulators should ensure that banks and financial institutions put in place policies for benchmark transition in a way that adheres to the 'treating customers fairly' framework, so that transitions should not be initiated arbitrarily, and there should be commercial certainty and fairness in transition measures. Failures by firms in ensuring fairness and certainty in benchmark transition could be subject to regulatory enforcement. Such regulatory enforcement would achieve concrete outcomes for user protection. This approach is preferable to imposing duties on administrators to oversee benchmark crises and transitions, as any enforcement against administrators would likely be in respect of procedural matters and achieve not much at all for real grievances of contracting parties.

It may be argued that 'nationalising' a benchmark is futile if the benchmark is systemically important beyond a domestic market, such as for the EU as a whole, and it would be inappropriate for any national regulator to administer it. The article suggests that where the EU is concerned, ESMA may be able to temporarily administer such an impaired benchmark due to systemic implications in Europe as it is a body that is building up administrative capacity in direct regulation and governance. Further, ESMA's regulatory objectives in prudential systemic risk oversight and consumer protection

\footnotetext{
${ }^{80}$ Such as the Federal Deposit Insurance Corporation's powers to resolve and liquidate banks in danger of failing or default under the Dodd-Frank Wall Street Reform and Consumer Protection Act 2010, section $203 \mathrm{ff}$.

${ }^{81}$ The Bank Recovery and Resolution Directive 2014; formally Directive 2014/59/EU of the European Parliament and of the Council of 15 May 2014 establishing a framework for the recovery and resolution of credit institutions and investment firms and amending Council Directive 82/891/EEC, and Directives 2001/24/EC, 2002/47/EC, 2004/25/EC, 2005/56/EC, 2007/36/EC, 2011/35/EU, 2012/30/EU and 2013/36/EU, and Regulations (EU) No 1093/2010 and (EU) No 648/2012, of the European Parliament and of the Council.

${ }^{82}$ The Banking Act 2009 and amendment sin view of the Directive above.
} 
in the EU would be able to support such a role of benchmark crisis management. ${ }^{83}$ However, what if the benchmark concerned originates from a third country outside of Europe? In such a situation, regulatory administration of a benchmark would need cooperation from other major jurisdictions. This article does not think that such obstacles may be simply overcome, but this difficulty is not a novel challenge given that all cross-border financial supervision suffers from the same challenge. As international coordination develops in areas such as prudential supervision, resolution frameworks and shadow banking governance, coordinating benchmark administration in a crisis should not be viewed as an insurmountable extension.

\section{Regulatory Capitalism, Appropriate Regulatory Design and Conclusion}

Regulating financial benchmarks is not to be assumed as a given or an unquestionable good and this article has adopted the position of advocating for a balance between regulatory governance and market-based governance for financial benchmarks that are determined to be 'regulable' due to their wide circulation, impact on stakeholder users and the market, and governance deficits in relation to their impact. Financial benchmarks are market innovations that overcome transactioncosts for many, but being market innovations, they are subject to the forces of capitalism. They evolve to meet supply and demand needs and are subject to competitive forces generating innovations and alternatives. As transactional management or micro-ordering is neither appropriate nor ideal for regulators, the role of financial benchmarks arguably has to be in part determined and shaped by market forces. However, regulation steps in where capitalism 'is out of control' ${ }^{84}$ such as where negative externalities are generated, or where tragedies of the commons occur. Braithwaite explains the role of modern regulation as 'steering the flow of events as opposed to providing and distributing ${ }^{85}$ hence having less of an ordering and top-down character but having a new ideological and technological character ${ }^{86}$ of providing governance in a non-exclusive governance landscape. ${ }^{87}$ Levi-Faur is of the view that regulation is a necessary complement to markets, and that ' $[t]$ he state is embedded in the economic and social order; any change in the state is expected to be reflected in the economy and the society, and vice versa. ${ }^{88}$ Hence in this age of regulatory capitalism, ' $[\mathrm{t}$ ] he new regulatory order is social, political, and economic. State, markets, and society are not distinct entities.

\footnotetext{
${ }^{83}$ Article 8, Regulation (EU) No 1095/2010 of the European Parliament and of the Council of 24 November 2010 establishing a European Supervisory Authority (European Securities and Markets Authority), amending Decision No 716/2009/EC and repealing Commission Decision 2009/77/EC.

${ }^{84}$ John Braithwaite, Regulatory Capitalism (Cheltenham: Edward Elgar, 2008) at 40.

${ }^{85}$ Above at 1.

${ }^{86}$ David Levi-Faur, 'The Global Diffusion of Regulatory Capitalism' (2005) 598 ANNALS of the Academy of Political Science 12, at 21.

${ }^{87}$ The idea of a decentred landscape in financial regulation and governance, see Mads Andenas and IRIS h-y Chiu, The Foundations and Future of Financial Regulation (Oxford; Routledge, 2014) at chapter 3.

${ }^{88}$ David Levi-Faur, 'The Global Diffusion of Regulatory Capitalism' (2005) 598 ANNALS of the Academy of Political Science 12 at 14.
} 
Indeed, regulatory capitalism rests on an understanding of the relations between state and market along a condominium (Underhill 2003)' ${ }^{89}$

Regulatory capitalism provides a lens to understand the necessary but proportionate role of regulation in providing a governance framework for regulable benchmarks. This also means that regulatory governance should not over-reach but indeed co-exist with optimal aspects of marketbased governance in order to support the social utility of financial benchmarks as transaction-cost reduction devices that facilitate access to finance and at the same time meet the public interest needs of market confidence and stability.

The article examines in a comparative fashion the three existing approaches in the UK, Europe and internationally (OICU-IOSCO), and observes that all three approaches, which share similar major features, achieve a mix between regulatory and market-based governance. This article supports the role of regulatory governance in enforcement against manipulative behaviour in relation to benchmarks, as all three approaches endorse. However, this article argues that the three approaches do not achieve an optimal balance between regulatory and market-based governance in relation to regulating benchmark administrators and benchmark submitters. This article has argued as to why the current regulatory regimes for administrators may be excessive and entail undesirable effects for secondary users of regulable benchmarks; and also why the current regulatory regimes need to be enhanced vis a vis submitters to meet regulatory objectives. Further, there is little agreement or convergence between the three approaches in terms of an optimal way to manage benchmark crises.

This article advocates alternative approaches that are rooted in a user-centric perspective of the nature of financial benchmarks. It is argued that the governance frameworks for regulable benchmarks should be based on protecting secondary user stakeholder interests in transaction-cost reduction and access to finance, and in so doing also meet the needs of maintaining market confidence and stability. This article recommends a reflexive approach to governing benchmark administration, supported by direct regulation of 'benchmark participation' which is widely defined in this article. It is envisaged that such an approach would avoid entrenching existing benchmarks but incentivise financial institutions to protect the integrity of benchmarks they use and generate. Such an approach would also avoid making regulable benchmarks less accessible and more expensive, prejudicing the very stakeholders that regulation intends to protect. Further this article advocates that direct regulatory muscle should be used to punish anti-social behaviour in benchmark manipulation and in situations of crisis where market stability is at stake, such as the temporary administration of an unstable benchmark and governing how benchmark transition should take place. In sum, this article has proposed an alternative governance framework which is believed to be more stakeholder-centric, more closely aligned with regulatory rationale and achieves the 'steering' of the benchmark market for continuous production of privately and socially useful financial benchmarks.

\footnotetext{
${ }^{89}$ Above at 14 .
} 